\title{
DESAPLICACIÓN E INAPLICACIÓN JURISDICCIONAL DE LAS LEYES EN CHILE: \\ EJERCICIO DE LA JURISDICCIÓN Y CONTROL CONCRETO DE CONSTITUCIONALIDAD*
}

\section{MANUEL NúŃEZ PoBlete**}

RESUMEN: La investigación describe las atribuciones de la jurisdicción ordinaria para desaplicar un precepto legal en ausencia y en presencia de antinomias (invalidatorias y no invalidatorias de la ley), y las confronta con la atribución del Tribunal Constitucional para declarar oficialmente la inaplicabilidad de un precepto legal. A partir del peculiar carácter concreto que la inaplicabilidad adopta tras la reforma de 2005, se intenta demostrar la existencia de competencias concurrentes entre la jurisdicción ordinaria y la constitucional, como asimismo sugerir el limitado sentido en que esta última es considerada un poder monopólico del Tribunal Constitucional.

PALABRAS CLAVE: Desaplicación - inaplicación - control de constitucionalidad de la ley - control de aplicación de la ley.

\section{JUDICIAL APPLICATION AND DISAPPLICATION OF LEGISLATION IN CHILE: EXCERCISE OF JURISDICTION AND CONCRETE JUDICIAL REVIEW}

\begin{abstract}
This paper describes the powers to not apply the statute law in presence or absence of constitutional infringement. The court's power to not apply the law is compared with the Constitutional Court's competence to deliver the non-applicability judgment. Finally, this re-
\end{abstract}

* El presente trabajo forma parte del Proyecto de investigación núm. 1090607, patrocinado por el Fondo Nacional de Desarrollo Científico y Tecnológico (Fondecyt) y del cual el autor es investigador principal.

Fecha de recepción: 20 de marzo de 2012.

Fecha de aceptación: 20 de octubre de 2012.

** Profesor de la Facultad de Derecho de la Pontificia Universidad Católica de Valparaíso. El autor agradece la asistencia del Licenciado Pedro Medina Alfaro, ayudante de investigación en este proyecto. Correo electrónico del autor: manuel.nunez@ucv.cl 
search explains, from the perspective of concrete judicial review, the shared and exclusive jurisdictional powers before the statute law.

KEY WORDS: Disapplication of statute law - Non Applicability Judgment - Judicial power - Judicial Review of Legislation - Procedural remedies.

\section{1) INTRODUCCIÓN}

Diversos problemas de la reciente práctica constitucional conducen a la reflexión sobre un tema que subyace a la revisión judicial de las leyes y que ha permanecido más bien implícito en la discusión sobre el supuesto carácter monopólico que tendrían las atribuciones del Tribunal Constitucional. Me refiero al concepto de desaplicación y, en general, a las atribuciones de los jueces para no dar aplicación a normas vigentes. Entre los problemas que invitan a la revisión de los contornos de dicho concepto se encuentran (i) la reestructuración de la declaración de inaplicabilidad tras la reforma constitucional de la Ley No 20.050, (ii) la construcción jurisprudencial del mentado instituto procesal constitucional, (iii) la renovada discusión sobre el alcance de la inaplicabilidad frente a los tratados internacionales, y (iv) el cuestionamiento de las atribuciones del Tribunal Constitucional para enjuiciar una ley cuando conoce de la impugnación de uno de sus actos de ejecución. La primera y la segunda de las cuestiones mencionadas abrieron la posibilidad de reemplazar el juicio abstracto de las antinomias por la revisión concreta de los efectos de la aplicación de un precepto legal a una gestión judicial determinada, permitiendo que el juicio de inaplicabilidad no suponga necesariamente un pronunciamiento sobre la validez constitucional de las normas en cuestión. El tercer problema, surgido a partir de la admisión de la declaración inaplicabilidad de "tratados internacionales ratificados que se encuentren vigentes" (al examinarse la constitucionalidad del proyecto de ley de reforma de la Ley orgánica núm. 17.997) ${ }^{1}$, ha conducido a redefinir el sentido de la inaplicabilidad y el carácter monopólico o difuso que tiene esta función cuando ella se asocia a la Constitución. Por último, el cuarto de los fenómenos anotados, el control de las llamadas "leyes pantalla" y su respuesta con ocasión de la revisión de la reforma de la Ley orgánica núm. 17.997, ha conducido igualmente a repensar el problema de las atribuciones que tienen los jueces para no aplicar las normas que, por formulación o por aplicación, son contrarias a la Constitución.

STC rol núm. 1.288, 25 de agosto de 2009. 
El presente estudio pretende definir los contornos conceptuales de la desaplicación de las leyes dentro del marco del Derecho constitucional chileno, examinando su proximidad con la competencia para declarar la inaplicabilidad de las leyes y, a partir de ello, ensayar una fórmula explicativa sobre las capacidades que tienen los jueces para dejar sin aplicación ciertas manifestaciones de la legalidad sin romper con los principios propios del Estado de Derecho y, en particular, con el deber de sumisión del juez a la ley. Tal como lo sugiere su título, este trabajo se centra en las atribuciones aplicativas del juez, sin profundizar en otras dimensiones de su potestad. Dado que el estudio se orienta a reformular las premisas desde las cuales se entiende la declaración de inaplicabilidad, el enfoque tiende a concentrarse en la aplicación de normas como elemento sustantivo de la función jurisdiccional. Esto implica que, para los efectos de esta investigación, el concepto de jurisdicción se maneja principalmente desde su dimensión aplicativa de normas (en su sentido más amplio) y mediante esa forma razonada y compleja del discurso preceptivo que llamamos sentencia. Con esta aclaración pretendo por una parte anticiparme a cualquier crítica sobre el reduccionismo de que pudiera adolecer una concepción de la jurisdicción centrada en la noción mecánica de la aplicación -previa subsunción de las leyes (Coing 1961, pp. 252 y ss.). Por otra parte, pretendo explicitar una premisa que aquí resulta fundamental y que no es otra que la indisoluble unión que existe entre jurisdicción y aplicación, de modo que aquella no puede comprenderse sin esta. Como se sostiene en dos obras importantes para la reflexión nacional sobre la actividad jurisdiccional, es consustancial a la jurisdicción el caso concreto que permite al juez llegar a la norma (Cerda 1992, 91), dado que la jurisdicción es precisamente una forma discursiva centrada en la adecuación de las normas a las circunstancias relevantes de ese caso (Marinoni, Pérez y Núñez 2010, 41).

\section{2) ¿QUÉ ES LA DESAPLICACIÓN?}

Lo propio de la decisión jurisdiccional radica en la capacidad o, propiamente, en la potestad de resolver un caso fundamentando la decisión en razones dadas anteriormente por otro órgano y que no se pueden desobedecer porque son obligatorias. Parafraseando la vieja fórmula romana (Dig. 2, 2.1), el magistrado aplica el Derecho que un tercero estableció para las partes de la contienda. En un concepto restringido de las fuentes jurídicas, ese tercero solo puede ser el Estado (legislador, constituyente, reglamentario o, al fin de cuentas, el soberano), mientras que una mirada más amplia también reconoce como fuentes creadoras a la comunidad (vulgar o forense, que modela ciertas costumbres y principios obligato- 
rios), a las propias partes del proceso (que pueden haberse dado anticipadamente las reglas para solucionar el conflicto), y hasta los propios tribunales de justicia. En lo que concierne a las fuentes formales de origen estatal "fuentes-acto" en la conocida versión de Mortati (1991, p. 318) o Crisafulli (1993, pp. 38 y ss.) corresponde al juez fallar el asunto sometido a su conocimiento aplicando la norma positiva que corresponde al caso. Si no aplica la norma (en términos positivistas, si no hay coincidencia entre la norma individual de la sentencia y la norma general, Kelsen 1995, p. 275), su sentencia es revocable o anulable, según sea el recurso procesal de que disponga el agraviado con esa decisión. La revisión judicial de esa decisión, vista en la perspectiva ilustrada moderna, asegura que los jueces -en tanto poder del Estado- se mantengan y resuelvan sus casos dentro de los márgenes fijados por el legislador que, dadas ciertas condiciones, se presume que actúa por el pueblo. Desde esa muy conocida perspectiva, el juez aplica y no crea la ley, todo lo cual resulta además muy conforme con el principio democrático según el cual la ley es obra de los representantes del pueblo.

En los términos recién resumidos, para no aplicar un precepto legal vigente (o a sus equivalentes sustantivos), el juez debe tener una buena razón. Estas buenas razones van desde las más sencillas, como la ausencia de la condición de aplicación de la norma (Nino 1995, p. 76), hasta explicaciones más complejas que presuponen la identificación e interpretación de otras normas que, por ser especiales, o más favorables o simplemente más coherentes con el resto del ordenamiento, excluyen la aplicación de un precepto legal determinado. La figura de la desaplicación, del modo en que se explicará a continuación, permite comprender el alcance con que operan estas justificaciones, sus límites y sus relaciones con los instrumentos constitucionales para controlar la constitucionalidad de las leyes.

Por desaplicación entendemos aquí la omisión fundada y legítima del juez de resolver conforme a los criterios indicados en una norma dada. Es fundada porque ni es obra del arbitrio ni de la ignorancia del juez, y es legítima porque a través de ella el juez se mantiene dentro de la juridicidad. La actuación dentro del campo de la juridicidad, que presupone "una interpretación justificable teóricamente, según los métodos de la ciencia jurídica" (Rodríguez y Ossandón 2008, p. 197) o "una interpretación razonable y posible de la ley" (Pedreira 2007, p. 113), excluye otras formas torcidas de desaplicación que caen dentro de las conductas prevaricadoras.

De la no aplicación de la norma solo se sigue un resultado diverso en la decisión del asunto, manteniéndose inalterada la vigencia y la validez de la regla desaplicada.

La descripción del instituto se acerca a la que dieron décadas atrás los autorizados publicistas Mortati y Guarino. El primero, en sus Instituciones de Derecho público intentó definir, en sede administrativa, la desaplica- 
ción como "el poder de no aplicar a una hipótesis de hecho individual un acto determinado que (...) permanece válido y eficaz para otros casos u otros efectos" (Mortati 1991, p. 299). El segundo, escribió que estamos en presencia de la desaplicación "cuando el acto debe ser considerado irrelevante respecto a un caso concreto y en relación al cual no produce los efectos que habría debido producir" (cit. en Pagotto 2008, p. 15). De acuerdo con esta concepción, la desaplicación es una figura jurisdiccional particular que solo afecta la eficacia de una norma y que se diferencia de decisiones que afectan su vigencia (como la suspensión y la derogación de las leyes) o su validez (como la anulación). Hay que subrayar que la desaplicación es una modalidad de la actuación jurisdiccional, distinta de la dispensa legislativa y administrativa (figura esta última de aparente origen canónico) en virtud de la cual el legislador o la Administración excusan la aplicación de una norma general a una situación particular dejando la norma dispensada vigente para el resto de los casos ${ }^{2}$.

El concepto que acaba de ser presentado no diverge mucho del que ha utilizado la doctrina administrativista comparada y la jurisprudencia nacional explicando las atribuciones de los jueces para no aplicar los reglamentos administrativos ilegales. En el Derecho administrativo español, Dómenech señala que "[i]naplicar una norma jurídica consiste, sencillamente, en prescindir de la misma para resolver un caso en el que tenía vocación de ser aplicada. Se resuelve sin observar la norma; se actúa en un caso concreto sin ajustarse a lo dispuesto en ella. El sujeto que inaplica la norma no queda obligado, en principio, a actuar del mismo modo en el futuro, y esta actuación tampoco vincula a otros sujetos. Como mucho, la inaplicación tiene el valor vinculante que cada ordenamiento jurídico asigna al precedente. Por eso se dice que "la inaplicación tiene un mero efecto inter partes" (Dómenech 2001, p. 61). En sentido similar, la doctrina francesa se ha referido a la excepción de ilegalidad, indicando que la capacidad de descartar las aplicación de los actos administrativos ilegales posee tres interesantes rasgos característicos: primero, que la decisión del juez no afecta la validez del acto; segundo, que a diferencia del contencioso de anulación, la excepción de ilegalidad puede ser invocada frente a cualquier tribunal; tercero, que la excepción puede ser hecha valer en cualquier tiempo (de Laubadère, Venezia y Gaudemet 2000, p. 105).

La jurisprudencia nacional conoce bien la figura de la desaplicación de los reglamentos ilegales. Durante la vigencia de la Constitución de 1925 , en plena polémica sobre los efectos de la ausencia de los tribunales contencioso administrativos, la supuesta falta de jurisdicción de los tribu-

2 En Chile, las dispensas legislativas, llamadas en otras latitudes "leyes sanatorias", liberan la posible invalidación de ciertas actuaciones mediante la declaración, ciertamente retroactiva, de su conformidad con el ordenamiento jurídico. En contra de estas leyes de validación, véase Soto Kloss (1996), pp. 101 y ss. 
nales ordinarios no impidió que estos últimos se atrevieran a no aplicar reglamentos ilegales ${ }^{3}$. Igualmente, bajo la vigencia de la Constitución de 1980 (cuya reforma del año 1989 eliminó la referencia a los tribunales administrativos del art. 38 de la Constitución), se resolvió que la desaplicación es una hipótesis distinta de la anulación: "[l]a disposición de un reglamento en contradicción con la ley respectiva carece de fuerza legal y no debe aplicarse, aunque se haya dictado so pretexto de aclarar o interpretar esta última" ${ }^{4}$. Esta práctica es notable, pues a diferencia de lo que sucede con el Derecho administrativo español ${ }^{5}$, en el Derecho chileno no existe habilitación expresa a favor de la jurisdicción.

En el Derecho comunitario también se conoce una figura similar. Se trata de la no aplicación de la normativa interna, incluida la legislación, en preferencia de la normativa comunitaria. Como se sabe, en virtud del principio de primacía del Derecho comunitario sobre el Derecho nacional "los jueces nacionales que conocen de un asunto en el marco de su competencia están obligados a aplicar íntegramente el Derecho comunitario y a proteger los derechos que este confiere a los particulares dejando sin aplicación toda disposición de ley nacional eventualmente contraria a aquél, ya sea anterior o posterior a la norma comunitaria"6. Esta obligación de "directa desaplicabilidad", reverso de la directa aplicabilidad del Derecho supranacional (Sorrentino 1996, p. 26), si bien exige la no aplicación de la norma interna no supone necesariamente un juicio de validez sobre aquella. Este último juicio, es el propio de la obligación de depuración del ordenamiento y se hace efectivo a través de otros cauces institucionales, tales como la derogación o, de haberla, la declaración de inconstitucionalidad. En aquellos países que cuentan con instrumentos de control de constitucionalidad, la ausencia del juicio de validez ha conducido a parte de la doctrina a sugerir el esquema interpretativo de la preferencia, en reemplazo del juicio de validez/invalidez, para referirse a la desaplicación de la normativa interna (Guzzetta 1994, p. 161). Este esquema interpretativo, asociado a la especialidad antes que a la jerarquía, permite que cualquier juez pueda dejar sin aplicación una ley sin recurrir

3 Entre otras véanse, Corte Suprema, sentencia de 17 de abril de 1962, Caja de Previsión de Empleados Particulares, R.D.J. LIX 2a.1a., pp. 109 y ss.; Corte Suprema, sentencia de 9 de marzo de 1961, Ojeda C., Enrique, R.D.J. LVIII 2a.1a., pp. 27 y ss.; Corte Suprema, sentencia de 6 de abril de 1961, Schwarze c. Marin, R.D.J. LVIII 2a.1a., pp. 57 y ss. Sobre el tema puede consultarse con provecho la relación de CORDERo (1995), pp. 150 y ss. Corte de Apelaciones de Antofagasta, sentencia de 30 de septiembre de 1991, R.D.J. LXXXVIII 2a.2a., pp. 117 y ss. (cons. $\left.4^{\circ}\right)$.

5 El artículo $6^{\circ}$ de la Ley orgánica del Poder Judicial 6/1985, de 1 de julio de 1985, dispone que "[l]os jueces y Tribunales no aplicarán los Reglamentos o cualquier otra disposición contrarios a la Constitución, a la ley o al principio de jerarquía normativa".

$6 \quad$ Tribunal de Justicia de la Comunidad Europea, asunto 106/77, Amministrazione delle Finanze dello Stato c. SpA Simmenthal, sentencia de 9 de marzo de 1978, ap. 21. Cito desde la versión castellana contenida en Alonso García (2001), p. 530. 
a la jurisdicción constitucional a través del expediente de la cuestión de constitucionalidad (Zagrebelsky 1990, p. 140 y Alonso García 1995 pp. 218 y ss.).

En los conceptos recién transcritos hay gruesas coincidencias, aunque no siempre hay consenso en torno a si la desaplicación es producto de un juicio de validez o de un simple juicio de pertinencia, entendiendo por juicio de validez a aquel que constata una contradicción insalvable que solo se soluciona con la modificación o supresión de las normas que están en conflicto. Para los efectos de esta exposición, se ordenarán primero los casos en que no hay juicio de validez, para posteriormente examinar aquellos en que sí podría haberlo. Hecho eso se confrontará la desaplicación, como atributo de todos los jueces, con el poder declaratorio de la inaplicabilidad, que la reforma de la Ley núm. 20.050 radicó en el Tribunal Constitucional.

\section{3) DESAPLICACIÓN EN AUSENCIA DE ANTINOMIA Y EN PRESENCIA DE ANTINOMIAS NO INVALIDANTES}

A menos que el juez administre justicia al interior de un ordenamiento ideal (es decir, completo, coherente y sistemático), es muy posible que en dicha función se encuentre con contradicciones entre normas. Según enseña la teoría del Derecho, las contradicciones a las que se enfrentan los jueces van mucho más allá de la simple oposición entre preceptos. En efecto, los diversos matices aconsejan, para identificar sus proyecciones dentro de la función judicial, separar las diversas formas de contradicción y, dentro de las llamadas antinomias, discernir aquellas que son reales de las que son aparentes. Un intento útil de sistematización es el que propuso Engisch en la década de los cincuenta, al identificar las antinomias como la segunda de cinco tipos de contradicciones dentro del orden jurídico: (a) las contradicciones técnico legales, (b) las contradicciones entre normas, (c) las contradicciones de valoración, (d) las contradicciones teleológicas, y (e) las contradicciones de principio (Engisch 2001, pp. 189 y ss.). Para Engisch, la contradicción entre normas, que para el positivismo constituye la quintaesencia de la jurisdicción constitucional, es una más de las contradicciones que deben enfrentar los jueces. Esto último no deja de ser significativo, pues el juicio de constitucionalidad se incardinaría básicamente en una de las hipótesis de contradicción, permaneciendo la decisión del resto de las antinomias en el dominio de la legislación o, en lo que interesa a esta investigación, en el dominio de la jurisdicción ordinaria.

En cuanto conflicto de normas, las antinomias han sido especialmente atendidas por la literatura iusfilosófica y, particularmente, por la posi- 
tivista. Entre las diversas formas de comprender su sentido (véanse por ejemplo Bobbio 1993, pp. 213 y ss., Kelsen 1995, pp. 273 y ss.), resulta particularmente útil a los efectos de la presente investigación la propuesta de separación de Luigi Ferrajoli. En sus Principia iuris indica que las antinomias pueden comprenderse en un sentido fuerte y en otro débil. En el primer sentido "estructural", "fuerte" o "estricto" las antinomias resultan del contraste sustancial entre un precepto legal y otra "norma sustancial" sobre producción de normas (Ferrajoli 2007, p. 684), de modo tal que puede decirse que el precepto en cuestión se encuentra viciado. De acuerdo con Ferrajoli, la antinomia es un vicio del que se deriva la nulidad de una de las normas en conflicto: "[e]l rasgo característico de las antinomias reside por tanto en la producción inválida de normas ilegítimas debido al contraste con las normas sustanciales sobre su producción" (Ferrajoli 2007 , p. 686). En consecuencia, el único modo de superar la contradicción consiste en la supresión de alguna de las normas en conflicto.

El sentido débil de las antinomias, en cambio, comprende las contradicciones entre normas del mismo nivel (solubles a través de los criterios de especialidad o temporalidad) y un "tertium genus" de antinomias de tipo "débil-fuerte" que consisten en la contradicción de normas de diverso nivel y en las que, no obstante existir de alguna forma el vicio, este último es "directamente superable a través de la aplicación de la norma superior y la desaplicación de la norma inferior, dejada en vigor no obstante ser reconocida como inválida" (Ferrajoli 2007, p. 690). A diferencia de las antinomias invalidantes, en las antinomias débiles el conflicto internormativo puede ser resuelto para el caso concreto por el mismo operador judicial que conoce del asunto (Ferrajoli 2007, pp. 688 y ss.).

A continuación, y sin el ánimo de ser exhaustivos, se presenta una breve relación de las hipótesis más comunes de desaplicación que no presuponen una contradicción que afecte la validez de la norma. Que no haya compromiso de la validez de alguna de las normas en conflicto conlleva, como ya se ha insinuado anteriormente, que el juicio sobre la aplicación de las normas o sobre la determinación de cuál es el Derecho que resuelve el caso corresponde a cualquier juez como parte fundamental de las funciones jurisdiccionales. Para decirlo en términos carneluttianos, es suficiente la intervención procesal normal del juez de la causa, no siendo necesaria la incoación de un "super proceso" ante un "super juez" que sea responsable de juzgar la validez de las reglas en conflicto (Carnelutti 1961, p. 209).

Como se verá más adelante, en el campo de las antinomias débiles o no invalidantes es posible identificar algunas hipótesis básicas y otras más complejas. Antes de explicar esas figuras, es preciso detenerse en la explicación de algunos casos simples de desaplicación que en principio no suponen antinomias pero que, dadas ciertas condiciones de interpretación, pueden conducir a ellas. 


\section{1.) DESAPLICACIÓN SIN ANTINOMIA}

Entre las hipótesis más básicas de desaplicación figuran la no aplicación por anomia (esto es, por falta de algunos elementos normativos que completan la eficacia de la norma ${ }^{7}$ y la no aplicación por simple impertinencia (la norma simplemente no se aplica porque no ordena la solución del caso). La no aplicación por anomia, da cuenta de una normatividad incompleta o, como se dice en el Derecho internacional, no autoejecutiva.

La desaplicación por falta de pertinencia es más compleja de lo que parece. En efecto, a ella puede llegarse de modo voluntarista, mediante ejercicios de acomodación interpretativa o ella simplemente puede derivar, por la misma vía interpretativa, en alguna forma de antinomia. Un buen ejemplo de lo primero se encuentra en los esfuerzos interpretativos que por años la judicatura ordinaria ha intentado con el art. 2331 del Código Civil. A través de estos esfuerzos, los tribunales han logrado que dicha norma dijera lo que no decía, configurando así otro caso de legalidad que, según la fórmula acuñada por Domínguez y Domínguez, "la jurisprudencia se llevó" 8 .

Como se sabe, el art. 2331 de Código Civil es un reflejo de la filosofía original del Código decimonónico que no daba cuenta del derecho a la reparación del daño moral. Contra la letra de la mentada norma civil, la Corte de Santiago resolvió en 1991 que "tal precepto debe interpretarse restrictivamente, por ser una excepción al principio general del artículo 2329 del mismo Código [Civil]", añadiendo que "[a]tentaría, pues, a los principios generales del derecho, contenidos por ejemplo en el artículo 2329 ya citado, y a la equidad natural que un hecho vejatorio, constitutivo no solo de delito civil sino incluso de uno penal, pueda quedar, a diferencia de lo que sucede con un cuasidelito, sin que se indemnice el daño moral sufrido por el ofendido" 9 . Nótese, que en este caso, cómo la interpretación "restrictiva" conduce a la inaplicación de la norma en cuestión. Posteriormente, la Corte Suprema declaró que: "como ya lo ha resuelto

$7 \quad$ Este ha sido, por ejemplo, el caso de las normas que regulan la intervención del Ministerio público (civil) en primera instancia, las asambleas provinciales o los tribunales de lo contencioso administrativo bajo la Constitución de 1925. Las primeras fueron advertidas como anomias en un estudio de Rubén Galecio (1966, pp. 137 y ss.). En el orden penal son frecuentes las anomias que frustran la aplicación de tipos penales integrados por elementos normativos. Este es el caso, por ejemplo, del tipo de falta consagrada en el art. 495 núm. 1 del Código penal, que se refiere a la contravención de las reglas para la conservación del orden público y que falla cuando dichas reglas no son dictadas por la autoridad administrativa. Otro ejemplo es el producido con la vigencia de la Ley núm. 20.603 y los fallos contradictorios de la Corte de Apelaciones de Iquique, 16 de junio de 2012, rol núm. 50-2012 y Corte de Apelaciones de San Miguel, 13 de agosto de 2012, rol núm. 286-2012.

8 Según la terminología acuñada en el conocido ensayo de Domínguez y Domínguez (1991).

9 Corte de Apelaciones de Santiago, 16 de abril de 1991, Revista de Derecho y Jurisprudencia LXXXVIII, 2a., 4a., p. 30. 
este Tribunal, en más de una ocasión, el artículo 2331 del Código Civil se refiere a la indemnización pecuniaria por daño emergente o lucro cesante (...) pero no a la indemnización del daño moral, cuya fuente para impetrarla emana del artículo 2314 del Código Civil"10.

Como es fácil advertir, la primera de las sentencias citadas esconde bajo la "interpretación restrictiva" la no aplicación de la ley, mientras que la segunda inventa un sentido que claramente la norma no tiene. La interpretación modifica entonces el sentido de la norma impidiendo que esta sea aplicada a un caso que parecía fácilmente subsumible en el supuesto de hecho. Por ello no es raro que la doctrina civil haya sostenido que la jurisprudencia haya pasado "sobre la letra del artículo 2331" (Aedo 2006, p. 415) o, más radicalmente, que en materia de daño moral "el derecho civil chileno ha seguido un desarrollo doctrinario y jurisprudencial contra legem, que ha terminado con el principio desarrollado sistemáticamente por el Código de 1855, de que solo son reparables los daños patrimoniales" (Barros 2007, p. 297).

La inteligencia de la norma civil comentada, que en los fallos anotados no traslucía una contradicción entre la Constitución y la ley, fue alterada con la intervención del Tribunal Constitucional. En efecto, después de la reforma de la Ley núm. 20.050, el art. 2331 del Código Civil fue objeto de varios requerimientos de inaplicabilidad ${ }^{11}$ que permitieron al Tribunal Constitucional entender que había una antinomia entre lo ordenado por el art. 2331 y los principios y valores que manda a proteger la Constitución. Interpretando el artículo en cuestión el Tribunal señaló que "el precepto legal impugnado tiene por objeto delimitar la tutela civil por responsabilidad en la lesión deliberada o negligente del derecho a la honra de otro, dando lugar a indemnización únicamente por aquellos dańos que pueda probarse que produjeron un empobrecimiento patrimonial de la víctima y negándola del todo cuando este daño material no puede probarse"12. Luego de intentar demostrar la relevancia de la eficacia normativa de la Constitución, la de sus principios y valores, y la necesidad de desechar "toda interpretación de las normas constitucionales que resulte contradictoria con los aludidos principios y valores rectores de la Carta Suprema"13, el Tribunal concluyó "[q]ue el efecto natural de la aplicación del precepto legal impugnado en estos autos -artículo 2.331 del Código Civil- es (...) privar a los atentados contra el derecho a la honra que no constituyan delitos específicos, de la protección de la ley"14.

Corte Suprema, 2 de abril de 1996.

Véanse las SSTC roles núm. 943, 10 de junio de 2008, y núm. 1.185, 16 de abril de 2009.

STC rol núm. 943, 10 de junio de 2008 , cons. $29^{\circ}$, con voto en contra.

STC rol núm. 943, 10 de junio de 2008 , cons. $32^{\circ}$.

STC rol núm. 943, 10 de junio de 2008 , cons. $37^{\circ}$. 
Como puede advertirse, a diferencia de los ejercicios argumentales más o menos satisfactorios de la justicia ordinaria, el Tribunal Constitucional no propone ninguna forma de entender la norma de modo compatible con la Constitución. Por el contrario, derechamente comprende el problema como una contradicción entre la norma (que excluye una determinada forma de resarcir un daño) y la Constitución (que obligaría a no excluir dicha forma de compensación). Se trata, en definitiva, de una antinomia derivada del enunciado mismo, mientras que para los jueces ordinarios el mismo enunciado podía entenderse de forma "restrictiva" o simplemente correctiva a fin de no aplicarse en un determinado proceso.

\section{2.) DESAPLICACIÓN POR ANTINOMIA NO INVALIDATORIA: EL PRO- BLEMA DE LA DEROGACIÓN TÁCITA}

Como se había adelantado más arriba, la fórmula de Ferrajoli (Ferrajoli 2007, p. 689) permite identificar entre las hipótesis simples de antinomia débil la desaplicación por preferencia de la norma especial sobre la particular (según el criterio de especialidad) o de la posterior sobre la anterior (según el criterio cronológico). En cualquiera de estos dos supuestos el juez decide la no aplicación de una norma como parte fundamental de un razonamiento de carácter jurisdiccional cuya identidad reposa, precisamente, en el discernimiento de la regla aplicable. Entre las hipótesis complejas de desaplicación sin antinomia invalidatoria se encuentran dos categorías de casos que pueden ordenarse del siguiente modo: la derogación tácita por virtud de la entrada en vigor de una norma de rango constitucional y las más numerosas figuras de desaplicación por un imperativo superior. Se excluye la derogación expresa porque esta forma de cesación de los efectos de la ley, al expulsar del ordenamiento a una de las reglas en conflicto, suprime la antinomia.

Con la llamada derogación tácita el problema constitucional reside en justificar la capacidad de los jueces ordinarios para constatar la cesación de la vigencia de las normas preconstitucionales. La discusión sobre este punto en Chile, bajo las antiguas y también bajo las nuevas vestiduras de la inaplicabilidad, ha girado en torno a dos ejes. El primero de estos ejes circula alrededor de la potestad de los jueces del fondo para constatar la derogación, mientras que el segundo lo hace en torno a la posibilidad de requerir la declaración de inaplicabilidad de preceptos anteriores a la Constitución. En el primer caso, el juez de la instancia podría afirmar la derogación dadas estas dos exigencias copulativas: (i) que exista una contradicción patente entre la norma legal y la Constitución y, por otra parte, (ii) que se trate de una norma rigurosamente anterior a la Constitución. La tesis que aquí se sostiene es que, dadas estas dos condiciones, el juez de la instancia haría uso de una facultad expresamente reconocida 
por la Constitución (disposición IV transitoria) ${ }^{15}$ y que, por añadidura, se sustenta en la natural atribución de definir el Derecho aplicable al caso o, para decirlo con palabras del propio Tribunal Constitucional, en la "facultad privativa de los jueces de la instancia [para] determinar las leyes con arreglo a las cuales deben pronunciar sus fallos" 16 .

La tesis aquí esbozada fue recibida por la Corte Suprema hasta principios de la década de los noventa en clave excluyente de la inaplicabilidad y, con posterioridad a esa fecha (fallo Campos Canales), como competencia concurrente entre los tribunales ordinarios y el máximo tribunal (Saenger y Bruna 2006, pp. 81-86). Aunque parte muy autorizada de la doctrina nacional considera "descaminado" el distingo entre inconstitucionalidad y derogación, negando la existencia de una cláusula constitucional derogatoria general (vid. Zúñiga 2006, p. 133), me parece que la facultad de constatar la vigencia de las leyes preconstitucionales puede todavía ser justificada si se precisan las dos condiciones ya anotadas.

$1^{\circ}$ Que la contradicción sea patente significa que la conclusión no puede ser objeto de una pluralidad de interpretaciones divergentes. En otras palabras, la antinomia debe ser apreciable desde cualquier punto de vista y no solo desde una parcialidad de procesos interpretativos. Si se admite que en la técnica normativa la regla general es la derogación expresa y precisa, y que la derogación tácita es la excepción, entonces la necesidad de flagrancia o frontalidad de la colisión normativa es la principal garantía de seguridad que tienen los súbditos de la ley frente al juez. Ahora bien, cuando una de las normas en conflicto es la Constitución, usualmente pródiga en conceptos generales y de significado variable en el tiempo, los casos en los que se cumpla con este requisito serán ciertamente excepcionales. En efecto, la naturaleza "incompleta" de varios de los preceptos constitucionales (que no por eso son menos jurídicos, para utilizar la terminología difundida por Nieto en el mundo hispanoparlante a principios de los años ochenta $)^{17}$, hace que la contradicción entre enunciados normativos y sus correspondientes significados no sea siempre nítida. Así por ejemplo, la disputa por la supuesta contradicción entre la Constitución y ciertas normas del Código Penal (art. 450), del Código Tributario (el antiguo art. 116), del Código Civil (art. 2331) o del DL núm. 2.695 de 1979, carece de la claridad que precisa el juez ordinario para constatar, sin más, la cesación de la vigencia legal por la vía de la de-

15 Cuya frase "y seguirán aplicándose en lo que no sean contrarias a la Constitución” es un indicio claro de la directa obligación judicial de no aplicar esas leyes preconstitucionales en lo que sí sean contrarias a la Carta Fundamental. En sentido similar, la disposición V transitoria, en la medida en que salva la vigencia de las leyes preconstitucionales que invaden el dominio del reglamento, también confirma la fuerza derogatoria de la Constitución.

17 Nieto (1983), pp. 383 y ss. 
rogación. Por el contrario, la completa oscuridad de la antinomia explica una abultada cadena de contradicciones dentro de la judicatura ordinaria y entre esta y la judicatura constitucional ${ }^{18}$. Un ejemplo de claridad en la configuración de una antinomia sobrevenida se encuentra en el DL núm. 2.186. Los artículos 15 y 17 de este cuerpo normativo, vigente desde el año 1978, todavía se refieren al pago imperativo en cuotas de la indemnización provisional, posibilidad expresamente excluida por el art. 19.24 de la actual Constitución. Para esta última norma, el pago diferido de la indemnización por la expropiación no procede (por lo menos para las expropiaciones perfeccionadas con posterioridad a esa misma fecha) ${ }^{19}$, sin el acuerdo previo del expropiado. $2^{\circ}$ Que se trate de una norma rigurosamente anterior a la Constitución exige que el legislador no haya manifestado su intención de reconocer la vigencia de la norma, hipótesis que no se cumple cuando se trata de precepto legal que ha sido expresamente modificado con posterioridad a la entrada en vigor del instrumento constitucional. Este último sería el caso, por ejemplo, del art. 15 del DL núm. 2.695, dado alguna vez por derogado en circunstancias de haber sido expresamente modificado el año $1996^{20}$.

\subsection{1.) Competencia del Tribunal Constitucional para pronunciarse en inaplicablidad respecto de normas preconstitucionales}

Después de la reforma del año 2005 pudo pensarse que la competencia para constatar la derogación le pertenecería en forma exclusiva y excluyente al juez de la instancia de modo que el Tribunal Constitucional sería incompetente para pronunciarse, vía inaplicabilidad, respecto de preceptos legales anteriores a la entrada en vigor de la Constitución de 1980 (primera forma de derogación) o a cualesquiera de sus reformas posteriores (segunda forma de derogación por antinomia sobrevenida). En efecto, tras la entrada en vigor de esa reforma la declaración de inaplicabilidad (art. 93.6 de la Constitución) es condición sine qua non para la declaración de inconstitucionalidad que la propia Constitución proclama como causa asimilable (aunque no enteramente equivalente) a la derogación con efectos ex nunc del precepto legal cuestionado. De este modo,

18 También se cuentan entre los casos de derogación el antiguo artículo 25 de la Ley núm. 16.643 sobre abusos de publicidad y el art. 44 Ley de Cheques. Respecto a la norma de la antigua Ley de abusos de publicidad, véase Corte de Apelaciones de Valparaíso, sentencia de 26 de julio de 1997, rol núm. 11628-97. Respecto del artículo 44 de la Ley sobre cuentas corrientes bancarias y cheques, véanse, entre muchos otros, Corte de Apelaciones de Iquique, 3 de diciembre de 1998, Gaceta Jurídica 222, pp. 103 y ss.; Corte de Apelaciones de Punta Arenas, 30 de diciembre de 1999, Gaceta Juridica 235, pp. 145 y ss. En todos estos fallos se estimó que la Constitución habia derogado tácitamente las disposiciones legales mencionadas.

19 Véase la STC rol núm. 552, 11 de marzo de 2008.

20 Art. único, núm. 7, de la Ley núm. 19.455 (D. Of. de 25 de mayo de 1996). 
siendo la declaración de inaplicabilidad y la declaración de inconstitucionalidad dos institutos diferentes (el núm. 7 del art. 93 constitucional exige que el precepto legal se encuentre vigente), habría sido posible concluir que el Tribunal Constitucional posee solo estas dos competencias: declarar la inaplicabilidad de un precepto legal vigente o derogar un precepto legal vigente a través de la declaración de inconstitucionalidad, tertium non datur. Sin embargo, como se demuestra a continuación, este razonamiento no tuvo eco en la práctica desarrollada a contar del año 2006. Por el contrario, en el Tribunal Constitucional ha primado la idea según la cual no es relevante para el juicio de inaplicabilidad el carácter preconstitucional del precepto legal, como tampoco el que se trate de una norma derogada. Siendo así, es posible afirmar que frente a los preceptos legales anteriores a la Constitución y a las normas legales derogadas existe en Chile una clara superposición de competencias entre la judicatura ordinaria y la judicatura constitucional especial.

Se ha explicado en la doctrina comparada que los tribunales constitucionales pueden pronunciarse sobre la regla preconstitucional, pues en tal caso se configura simultáneamente una hipótesis de derogación (tácita) y otra de invalidez sobreviniente (por suceder a la norma invalidada una norma de superior jerarquía, de Otto 1988, 79 y Gascón 1994, 858). Por su parte, para argumentar el conocimiento de normas preconstitucionales el Tribunal Constitucional chileno ha ofrecido dos razones. La primera es formal: no es admisible la alegación de incompetencia, pues es el propio órgano el que define su competencia ${ }^{21}$. La segunda razón es bien descrita en un fallo de 2009, el Tribunal señaló que para desechar la alegación de incompetencia por referirse el caso a normas supuestamente derogadas en forma tácita: "basta recordar la doctrina permanente del Tribunal Constitucional, conforme a la cual el mismo ha sostenido que aunque la entrada en vigencia de un precepto legal sea anterior a la de la norma constitucional con la que resultaría contraria en su aplicación judicial, ello no es obstáculo para su impugnación por la vía de la acción de inaplicabilidad. Este medio de control de constitucionalidad tiene por objeto evitar la aplicación en una gestión judicial (...) de uno o más preceptos legales que eventualmente puedan recibir aplicación y produzcan, en tal caso, efectos contrarios a la Constitución, para lo cual la intervención de esta Magistratura es insustituible. En efecto, si el Tribunal Constitucional se inhibiera de actuar porque en la gestión judicial en que incide el requerimiento se ha planteado la derogación tácita (...) bien pudiera ocurrir que (...) el tribunal de la causa los estimara vigentes, con lo que se eludiría la decisión, que es propia de esta Magistratura Constitucional, en torno 
a la aplicación conforme o contraria con la Constitución de un precepto legal"22.

Esta competencia del Tribunal para conocer de la aplicación de preceptos anteriores a los textos constitucionales se suma a la competencia que la misma Magistratura se ha atribuido para conocer de inaplicabilidades intentadas contra preceptos legales suprimidos mediante la declaración de inconstitucionalidad (STC rol núm. 1552, 28 de octubre de 2010) o expresamente derogados por el legislador (STC roles núms. 1309 y 1469,4 de noviembre de 2010223.

\subsection{2.) La competencia no exclusiva en su contexto: algunas exigen- cias adicionales y sus dificultades prácticas}

Los criterios anotados parecen enfilar la construcción de la competencia propia de la inaplicabilidad hacia un derrotero que es conocido y que suele conducir al Tribunal Constitucional hacia la función de revisor de decisiones judiciales antes que en contralor de la legislación: el carácter concreto de la inaplicabilidad. En efecto, de los razonamientos recién transcritos fluye la naturaleza recursiva de la inaplicabilidad, a través de la cual se vigila y precave que los jueces no vayan a aplicar un precepto legal tácitamente derogado o suprimido por la declaración de inconstitucionalidad violando la Constitución (en el último caso concediendo ultraactividad a una norma más allá de los límites constitucionalmente fijados para la declaración de inconstitucionalidad) ${ }^{24}$. Este modo de ver las cosas (y particularmente de concebir la inaplicabilidad en una dimensión recursiva) precisa, sin embargo, de dos condiciones adicionales: (i) que no se entienda que la capacidad de precaver la infracción a la Constitución por mor de aplicar una norma derogada o no aplicar una vigente le pertenezca exclusiva o monopólicamente al Tribunal Constitucional; y (ii) que el sistema conceda garantía de respeto y universalidad a favor de la decisión del Tribunal, ratificatoria o denegatoria de la vigencia del precepto (una

22 STC rol núm. 991, 29 de enero de 2009, cons. 50.

23 Este fallo revisó la jurisprudencia precedente sobre incompetencia del Tribunal Constitucional y que se expresó en fallos como la STC rol núm. 1.231, 9 de junio de 2009. Véase con detalle la relación que hace Henríquez 2012, pp. 202 y ss.

24

Véase la STC rol núm. 1552, 28 de octubre de 2010, cons. $6^{\circ}$ y ss. La declaración de inconstitucionalidad no es considerada como sinónima de la derogación y, por lo tanto, ella no admite la ultractividad "la expulsión del precepto legal del ordenamiento jurídico, en los términos referidos en la Constitución, importa una negación absoluta y definitiva de sus efectos, salvo de aquellos que la misma Constitución admite excepcionalmente por las razones ya expuestas. Extender dichos efectos más allá de lo expresamente previsto en la Carta Política (efecto ultractivo) importaría una evidente vulneración de su sentido y espíritu y una clara limitación a los fines previstos en la misma Constitución, sobrepasándola" (cons. $\left.10^{\circ}\right)$. 
cosa no puede ser y no ser al mismo tiempo: una misma norma no podría considerarse simultáneamente como vigente y derogada).

La primera de las condiciones anotadas se da cuando la facultad de determinar la vigencia se encuentra asociada a la de discernir el Derecho aplicable al caso. Esta facultad requiere ciertamente de recursos que permitan invalidar las decisiones judiciales que no reconocen la eficacia derogatoria de la Constitución. De allí que sea necesario revisar los tradicionales postulados que han excluido a la Constitución de la casación civil $^{25}$ y reforzar la eficacia constitucional de los recursos de nulidad que han proliferado en ámbitos como el laboral o el penal. La revisión de los postulados contracasacionales parece posible de conciliar con las prevenciones de la doctrina (me refiero particularmente al peligro del "demiurgo normativo" de Zúniga 2005, p. 18) si se exige la condición arriba explicada, esto es, que la constatación de la derogación presuponga una antinomia explícita o patente. Lo mismo cabría decir respecto de las exigencias necesarias para considerar que hay infracción de ley o errónea aplicación del derecho en el caso de los recursos de nulidad.

En cuanto a la garantía de respeto y universalidad a favor de la decisión del Tribunal Constitucional, es posible sostener que la ausencia de conexión orgánica entre la judicatura constitucional especializada y la ordinaria hace que en Chile no exista garantía de fidelidad y universalidad respecto de algo tan elemental para la seguridad jurídica como es la doctrina sobre la vigencia de las normas. La experiencia en casos como el artículo 450 del Código Penal, el antiguo artículo 116 del Código Tributario o los artículos 15 y 16 del DL 2.695 de 1979 (dudosos ejemplos de derogación por parecer, como se dijo, que la antinomia no es flagrante) demuestra la dispersión de la interpretación y la reciente doctrina comienza a insistir en las imperfecciones del diseńo que puede tornar en inútiles algunas decisiones de inaplicabilidad (Núñez 2012 y Silva 2012). Así, hay fallos de tribunales ordinarios que han estimado que los preceptos legales recién citados están derogados mientras el propio Tribunal Constitucional ha sostenido, antes o después, que se trata de normas vigentes $^{26}$. Incluso más, respecto de la mentada norma del Código Tributa-

Véanse las observaciones de Romero (2005), Silva (2007) y Gandulfo (2008), en contraste con la crítica que propone ZúNiga (2005).

26 Respecto del artículo 450 del Código Penal, véanse, entre otras, Corte de Apelaciones de Santiago, sentencia de 1 de junio de 1999, rol núm. 54.801; sentencia de 15 de noviembre de 2000 (citada en VAN WeEZel 2001); y sentencia de 11 de septiembre de 2009, rol 2122 2009. En contra, Corte de Apelaciones de Santiago, sentencia de 24 de junio de 2009, rol núm. 1194-2009, Corte Suprema, 13 de abril de 2009, rol núm. 8.158-2008 y Corte Suprema, 10 de enero de 2007, rol núm. 2.850-05. Mientras para el primer grupo de fallos se trata de una norma derogada por la Carta de 1980, para el Tribunal Constitucional (SSTC roles núm. 787, 18 de diciembre de 2007; núm. 829, 6 de marzo de 2008, y 825, 6 de marzo de 2008) se trata de una norma compatible con la Constitución y por tanto se encuentra 
rio, la declaración de inconstitucionalidad solo se justificaba si se trataba de una norma vigente, por lo que no había modo de entender que antes de esa declaración ya hubiese sido antes considerada derogada por los tribunales ordinarios.

Es preciso agregar que la garantía de fidelidad y universalidad hacia los dictados de la jurisdicción constitucional adquiere la misma importancia cuando el Tribunal desestima la contradicción de contenidos y, por lo tanto, valida la constitucionalidad de la norma cuestionada. Al desechar la inaplicabilidad por inexistencia de la antinomia, la señal debería ser clara: [si] no hay contradicción, [entonces] la norma existe y rige, y por lo tanto ni el requirente de autos ni cualquier persona debería volver a poner en duda de la vigencia de la ley. Solo si el Tribunal Constitucional decide variar su interpretación de la ley fundamental, a través de un overruling, sería posible discutir nuevamente la vigencia de la ley. Allende el carácter concreto de la inaplicabilidad (que desaconseja las generalizaciones, en palabras del propio Tribunal ${ }^{27}$, sería aquel un caso, como el de las inconstitucionalidades de forma, en que del raciocinio del Tribunal sería posible y legítimo extraer consecuencias generales y universales. Como no es posible que un mismo precepto legal se encuentre, al mismo tiempo, vigente para unos y derogado para otros, la respuesta debería ser entonces unitaria y obligatoria para todos los operadores de la ley. Parafraseando a García de Enterría, que sugiere como prueba de la eficacia normativa de la Constitución que todo juez debe realizar un juicio "positivo" de constitucionalidad (solo aplica aquellas normas que considera constitucionales, García de Enterría 1985, 66), los jueces estarían obligados a considerar afirmativamente la vigencia de la norma precedentemente validada por la judicatura constitucional. Desafortunadamente, como acaba de demostrarse, ello no siempre es así.

vigente. Entre las sentencias que habían declarado derogado el artículo 116 del Código Tributario (antes de su declaración de inconstitucional), véanse a título ejemplar, Corte de Apelaciones de Santiago, sentencia de 28 de septiembre de 2006, rol núm. 7201-01 y sentencia de 31 de diciembre de 2002, rol núm. 6439-98. Respecto del DL 2.695, cuya vigencia fue expresa y razonadamente ratificada en la STC rol núm. 707 de 25 de octubre de 2007, véase el notable fallo contrario de la Corte Suprema, sentencia de 28 de septiembre de 2010, rol 1018-09, cons. $15^{\circ}$ y ss. En esta última sentencia la Corte Suprema declaró, contra lo sostenido dos ańos antes por el Tribunal Constitucional, que "a lo menos las normas de los artículos 15 y 16 del mencionado cuerpo de leyes se encuentran orgánicamente derogadas, por aplicación de los principios de supremacía constitucional, aplicación directa de la norma fundamental y efecto derogatorio de sus disposiciones, respecto de aquellas que están en contradicciones con las contempladas en la norma constitucional, de forma tal que tampoco correspondería reconocerles vigencia en esta causa" (cons. $30^{\circ}$ ).

27 STC rol núm. 546, 17 de noviembre de 2006, cons. I.3: "no será siempre posible extraer conclusiones jurisprudenciales o doctrinas de carácter general acerca de la constitucionalidad o inconstitucionalidad de determinados preceptos legales". 


\section{3.) DESAPLICACIÓN POR ANTINOMIA NO INVALIDATORIA: DESAPLI- CACIÓN POR UN IMPERATIVO NORMATIVO SUPERIOR}

Una segunda hipótesis compleja de desaplicación es la que resulta de la obediencia hacia un imperativo normativo superior. Este imperativo puede tener el carácter de una obligación internacional, de una norma constitucional o, incluso, provenir de una interpretación judicial más autorizada dentro de la organización judicial nacional. A continuación se explicarán cada una de estas variedades de desaplicación.

\subsection{1.) Desaplicación por preferencia de una norma no nacional}

La obediencia hacia un imperativo internacional conduce a varias formas de desaplicación judicial que dejan indemne la validez de la norma no aplicada.

En primer lugar, es posible que el juez se enfrente ante una antinomia de normas internacionales (por ejemplo, entre el régimen de un tratado comercial y el de un instrumento de derechos humanos) y decida aplicar una en postergación de la otra. En este caso, en virtud del dédoublement o role splitting el juez doméstico obra como brazo nacional del Derecho internacional y, dada la incompetencia de aquel para invalidar las normas internacionales, no es posible sostener que haya un pronunciamiento de validez respecto de la norma no aplicada.

En segundo lugar, el juez en ciertos casos tiene la obligación de preterir la aplicación de una norma constitucional a favor de una norma internacional o, allí donde las hay, de una norma supranacional. Por ejemplo, estando plenamente vigentes las normas constitucionales y legales referidas a la pena de muerte, la aplicación de las mismas se encuentra severamente limitada (en sede judicial y administrativa) por los protocolos internacionales publicados durante el 2008 y el 2009, relativos a la aplicación de dicho castigo ${ }^{28}$. Que el juez nacional no aplique las normas constitucionales no implica que ellas carezcan de validez, sino solamente que se han tornado en ineficaces. Algo similar sucede con las normas legales, en virtud del llamado control de convencionalidad, que al no ser aplicadas o ajustadas en su interpretación a fin de mantener la sumisión del juez al Pacto de San José y a la doctrina de la Corte Interamericana de Derechos Humanos.

\footnotetext{
28 Se trata del Segundo Protocolo Facultativo al Pacto Internacional de Derechos Civiles y Políticos, destinado a abolir la pena de muerte (DS. núm. 249, de 15 de octubre de 2008, D. Of. de 5 de enero de 2009) y del Protocolo Facultativo a la Convención Americana de Derechos Humanos relativo a la abolición de la pena de muerte (DS núm. 252, de 20 de octubre de 2008, D. Of. de 16 de diciembre de 2008).
} 


\subsection{2.) Desaplicación por preferencia de una norma más favorable}

La necesidad de optar en el caso concreto por la aplicación de una norma más favorable, por aplicación del principio pro libertate o pro persona, puede conducir a la desaplicación de las normas concurrentes aun si estas son de superior jerarquía. Así, las normas más beneficiosas del Código Procesal Penal han de preferirse a ciertas normas constitucionales concurrentes en materia, por ejemplo, de libertad personal. Del mismo modo, si se está de acuerdo con la tesis según la cual en materia de derechos constitucionales el principio de jerarquía es sustituido por el de la norma más favorable, el juez puede preferir una norma constitucional nacional a la aplicación de un instrumento internacional y viceversa. En la doctrina nacional (Nogueira 2008, pp. 232 y ss.) e internacional de los derechos humanos (Cançado 2001, pp. 312-313) este parece ser el criterio generalizado, por lo menos en lo que se refiere al deber de aplicar la norma más favorable en materia de derechos fundamentales.

También podría considerarse dentro de esta categoría la desaplicación de normas constitucionales que contradicen otras normas constitucionales, asunto debatido por la doctrina (Bachof 1994, pp. 25 y ss.), como aconteció en nuestro país con un celebrado fallo del Tribunal Constitucional que adelantó la vigencia de las normas sobre la calificación judicial de las elecciones ${ }^{29}$.

\subsection{3.) Desaplicación por prevalencia de un criterio interpretativo formulado por un tribunal superior}

Una versión especial de esta forma de desaplicación por imperativo superior, sobre la que se volverá más adelante, se encuentra en el cumplimiento de las prevenciones interpretativas contenidas en las sentencias del Tribunal Constitucional. Este órgano jurisdiccional ha venido utilizando la difundida técnica de las sentencias interpretativas en los procedimientos de control preventivo y represivo (vía inaplicabilidad) con el fin de evitar la declaración de inconstitucionalidad o inaplicabilidad, respectivamente. Así por ejemplo, tratándose de la legislación procesal penal son numerosas las prevenciones interpretativas que condicionan la aplicación de la normativa legal de parte de los jueces con competencia en lo criminal. Una de estas prevenciones obliga a los jueces (o al menos eso se pretende) a entender que, a pesar de que la norma legal concede la apelación de una resolución al Ministerio Público, puede también apelar contra ella la defensa ${ }^{30}$. Si nos tomamos en serio esta prevención propia del control

29 STC rol núm. 33, 24 de septiembre de 1985.

30 STC rol núm. $1.001,29$ de enero de 2008 , cons. $20^{\circ}$. 
obligatorio de constitucionalidad (lo que tampoco, por desgracia, ha hecho el Tribunal) ${ }^{31}$, resulta que el juez debe inaplicar la norma del art. 132 bis en lo que a su claro tenor literal se refiere. Orientaciones interpretativas similares se encuentran en las decisiones de inaplicabilidad relativas a los delitos de peligro ${ }^{32}$ o al delito de microtráfico ${ }^{33}$, en el sentido que la decisión indica cuáles son los modos de aplicar la legislación que no producen un efecto contrario a la Constitución $\mathrm{y}$, a contrario, cuáles sí producen esos efectos y por lo tanto no pueden ser aplicados por el Tribunal. Aunque en doctrina se discuten los efectos de estas orientaciones hermenéuticas (incluso para el mismo órgano que conoce de la gestión en que se plantea el incidente) ${ }^{34}$, es claro que cualquier juez conocedor de la jurisprudencia constitucional y, desde luego, el juez que conoce de la gestión en que incide la sentencia de rechazo, puede ajustar sus decisiones a estos modos de entender el derecho aplicable. Si se reconoce valor vinculante a la "cosa interpretada" 35 que deriva de los procesos de control preventivo, ello conduce necesariamente a la desaplicación de uno de los sentidos posibles de atribuir al precepto legal o, en los casos más radicales (como el del art. 132 bis del Código Procesal Penal), a la completa desviación del tenor literal de la norma antes interpretada por el Tribunal Constitucional.

A las sentencias interpretativas de control preventivo y a las interpretativas de inaplicabilidad hay que añadir una tipología muy específica y todavía poco estudiada por la doctrina nacional. Se trata de un tipo de decisiones que podríamos llamar "declaraciones de esterilidad normativa" y que el Tribunal ha ensayado controlando preventivamente los tratados internacionales. A través de estas decisiones que podrían considerarse como una variante de las sentencias interpretativas, el Tribunal admite la constitucionalidad de un precepto internacional determinado a partir de su incapacidad para producir efectos en el ordenamiento interno. Así sucedió, por ejemplo, con la norma del 9.1 del Convenio 169 de la OIT, sobre aplicación de sanciones penales por las comunidades indígenas ${ }^{36} \mathrm{y}$ el art. 14 sobre propiedad ${ }^{37}$. Aunque es un tema que no puede profundi-

\footnotetext{
31 Véase paradigmáticamente la STC rol núm. 1.211, 16 de septiembre de 2008. Esta decisión es llamativa, pues es la desobediencia a la prevención lo que, precisamente, conduce a que no haya apelación. Hay que anotar que parte de la doctrina procesal ha considerado la obligatoriedad de etas prevenciones (Piedrabuena 2008, p. 207).

32 STC rol núm. 739,21 de agosto de 2007 , cons. $18^{\circ}$.

33 STC rol núm. 993, 13 de mayo de 2008, cons. $14^{\circ}$.

34 En Italia, fue la Corte de Casación (sentencia núm. 23.016/2004, de 17 de mayo de 2004) la que declaró que las llamadas "sentencias interpretativas de rechazo" no obligaban a los jueces del proceso desde el cual fue elevada la cuestión de legitimidad.

35 Véase Viala (2001), pp. 777 y ss. y, él mismo (1999).

36 STC rol 309, 4 de agosto de 2000, cons. 53․ Véanse en el mismo sentido las SSTC rol núm. 1.483, 29 de septiembre de 2009 y rol núm. 1.504, 3 de noviembre de 2009 .

37 STC rol 309, 4 de agosto de 2000 , cons. $48^{\circ}$.
} 
zarse aquí, es importante adelantar que a diferencia de lo que sucede con la legislación nacional o interna, en el caso de los tratados internacionales falla la competencia del Tribunal para formular reservas o declaraciones interpretativas al margen de los procedimientos constitucionales que reservan esa atribución al Presidente de la República (y marginalmente al Congreso Nacional). Esto último torna en discutibles, por no ser obigatorios, los efectos absolutos de este tipo de declaraciones hacia la jurisdicción ordinaria en materia de Derecho internacional.

\subsection{4.) Desaplicación de los criterios normativos rectores de la inter- pretación de la ley por aplicación de los principios y valores constitucionales}

En un sistema reglado de principios de interpretación de la ley (como acontece en el caso chileno), cada vez que el juez aplica los criterios generales de interpretación de la Constitución, y en particular la metodología axiológica que suele desviar la atención sobre el elemento gramatical, deja de aplicar las normas del Código Civil que otorgan preferencia a la letra en perjuicio de lo más cercano a los valores de la Constitución, esto es, el "espíritu de la legislación" 38 . En otras palabras, del mismo modo en que el pretendido monopolio del Tribunal Constitucional para juzgar las contradicciones entre las leyes y la Constitución es, como lo sostiene Luigi Ferrajoli, una forma de obligar al resto de los tribunales a dejar sin aplicación a la Constitución (Ferrajoli 2007, p. 690), el recurso a los valores constitucionales en la interpretación de las normas legales conlleva una invitación para dejar sin aplicación las normas del Código civil sobre interpretación de las leyes. ¿Existe acaso otra forma de entender la siguiente declaración del Tribunal Constitucional?: "es facultad privativa de los jueces de la instancia determinar las leyes con arreglo a las cuales deben pronunciar sus fallos, naturalmente en contrapunto con los derechos que recoge la Constitución y los tratados internacionales ratificados por Chile que se encuentren vigentes" 39 .

La eficacia directa de la Constitución en los procesos de interpretación de la ley, de modo que la atribución de significados de esta última se ajuste a la primera, puede conducir: (i) a la determinación del sentido que sea más coherente con las normas constitucionales (principio de la interpretación conforme), o derechamente (ii) a la rectificación del texto legal. La primera de estas consecuencias es admitida por la unanimidad de la doctrina, en tanto que la segunda ha sido advertida como un peligroso

\footnotetext{
38 Sobre la improcedencia de los criterios tradicionales de interpretación en la hermenéutica constitucional, vid. STC rol núm. 464, 31 de enero de 2006, cons. $6^{\circ}$.

39 STC rol núm. 1532, 24 de agosto de 2010 , cons. $7^{\circ}$, cursivas añadidas.
} 
despeńadero a favor del arbitrio judicial. Criticando la norma pertinente de la Ley orgánica española del Poder Judicial, que condiciona la cuestión de constitucionalidad a la imposibilidad de acomodar la norma a la Constitución ${ }^{40}$, Díez-Picazo escribía: “[e]ste punto de vista es erróneo. No hay relación entre planteamiento de constitucionalidad y posibilidad de acomodación (...) El artículo $5.1^{41}$ ha dicho ya que las leyes se interpretan según los preceptos y principios constitucionales. No tiene sentido repetir la misma idea en el artículo 5.3. Quiera ello decir que la acomodación de la norma al ordenamiento constitucional no se lleva a cabo por vía interpretativa en sentido estricto (búsqueda y determinación del sentido y significado), sino por una interpretación considerada en su sentido mucho más amplio. En mi opinión una actuación contra legem, es gravemente subversiva. Si la ley es inconstitucional que caiga por inconstitucionalidad y que la haga caer quien pueda hacerlo, pero introducir manipulaciones en leyes vigentes por mucho que se pretenda acomodarlas me parece especialmente grave" 42 .

En su extremo, la prevención de Díez-Picazo da buena cuenta de los riesgos de banalizar las capacidades correctivas de la legislación de parte de quienes poseen jurisdicción. Sin embargo -y sin trivializar esos riesgos no es posible negar que parte del progreso de un Estado de Derecho se debe, precisamente, a la capacidad creadora y correctora de la jurisdicción frente a la ley en el caso particular. La historia nacional de la responsabilidad civil por daño moral, de la reajustabilidad de las obligaciones dinerarias, de la sumisión de la Administración a la Constitución y a las leyes, por mencionar algunos de ejemplos paradigmáticos, muestran que el progreso de las instituciones jurídicas no es patrimonio exclusivo de la justicia constitucional.

\section{4) EL PROBLEMA DE LA DESAPLICACIÓN EN PRESENCIA DE ANTINOMIAS INVALIDANTES: DOCTRINA Y PRÁCTICA DE LOS TRIBUNALES}

El sentido más grave de las antinomias es aquel que presupone un vicio en una de las normas en conflicto, a saber, la falta de competencia, de procedimiento o de jerarquía. Así las cosas, el único modo de eliminar el conflicto consiste en la supresión de uno de sus protagonistas. En nuestro

\footnotetext{
40 Cuyo art. 5.3 dispone que "procederá el planteamiento de la cuestión de inconstitucionalidad cuando por vía interpretativa no sea posible la acomodación de la norma al ordenamiento constitucional".

41 "La Constitución es la norma suprema del ordenamiento jurídico, y vincula a todos los Jueces y Tribunales, quienes interpretarán y aplicarán las Leyes y los Reglamentos según los preceptos y principios constitucionales, conforme a la interpretación de los mismos que resulte de las resoluciones dictadas por el Tribunal Constitucional en todo tipo de procesos". Díez-Picazo (1985), p. 21.
} 
ordenamiento vigente, este acto de supresión es siempre un acto de ejercicio de poder, sea del Poder Legislativo (derogación) o del Poder Jurisdiccional (declaración de inconstitucionalidad). Estos actos de supresión o eliminación formal de la antinomia son claramente distinguibles de aquellos actos de inaplicación particular que, presuponiendo la antinomia, no la eliminan en general, sino que la juzgan en particular.

\section{1.) LA DOCTRINA NACIONAL}

En la teoría nacional este problema se ha discutido durante las últimas décadas bajo la etiqueta del llamado "control difuso" de las leyes, aunque desde mucho antes se venía discutiendo el problema general de las atribuciones de los jueces inferiores para dejar sin aplicación un precepto legal contrario, en la forma o en el fondo, a la Constitución. Así, mucho antes de que se conociera el término de control difuso (expresión de una dicotomía "ruinosa", según Ruiz Tagle 1998-1999), la literatura constitucional (Hunneus 1880, pp. 252 y ss. y Roldán 1913, p. 486) y procesalista (Ballesteros 1890, pp. 523 y ss.) de la Carta de 1833 se habían pronunciado por la negativa. Aunque la realidad ${ }^{43}$ y parte autorizada del foro ${ }^{44}$ porfiaban este dogma, la doctrina dominante defendía la inexistencia una norma que expresamente reconociese dicha facultad de los tribunales de justicia.

Durante el siglo XX, creado ya el recurso de inaplicabilidad por la Carta de 1925 y recibido prácticamente intacto por la Constitución de 1980, el dogma según el cual los jueces ordinarios carecían de facultades para no aplicar la normas contrarias a la Constitución, se reforzó con un argumento adicional: al haber sido radicada la competencia declaratoria de la inaplicabilidad en la Corte Suprema era todavía más indiscutible la incompetencia de los jueces de la instancia para dejar de aplicar los preceptos legales que se creyesen contrarios a la Constitución. En otras palabras, ahora que había norma expresa, ella debía interpretarse literal y restrictivamente a favor del órgano: el principio de juridicidad y dentro de este el principio de competencia deslindaba el sentido del principio de

43 Recuérdense, durante las primeras décadas de nuestra vida republicana, los numerosos casos de no aplicación deliberada de las rigurosas leyes penales castellanas o, con posterioridad a la entrada en vigencia del Código Civil, la aplicación judicial ultraactiva de Las Partidas.

A propósito de las supuestas atribuciones jurisdiccionales de una Comisión establecida por ley de 20 de enero de 1883 (que reproducía varios aspectos de la Ley de radicación de 4 de diciembre de 1866), cuyas decisiones no podían ser revisadas por los tribunales en la interpretación oficial, el fiscal Ambrosio Montt anotaba: “[u]n tribunal de este linaje no es posible en Chile, ni aun en las rejiones de Arauco; i si hai, cual se pretende leyes que lo hayan creado en circunstancia i por motivos especiales, esas leyes nacieron sin vigor el mismo día de su promulgación i no han debido guardarse como opuestas a los principios fundamentales de la Constitución” (MONTT 1895, 166). 
la fuerza normativa de la Constitución. Esta tesis predominó a partir de la entrada en vigor de la Constitución de 1925 y se mantuvo fuerte durante toda su vigencia (Andrade 1971, p. 633), aunque hay que advertir que contó entre sus detractores a uno de los más grandes juristas chilenos de la primera mitad del siglo XX, don Luis Claro Solar (Claro Solar 1934, p. 17). En la misma senda de Claro Solar, durante la Constitución de 1980 es posible encontrar voces que, antes y después de la reforma de 2005 también han salido en defensa de la facultad de los jueces para aplicar la Constitución sobre la legislación (Fernández 2001, Ríos 2002 y 2005, Martínez 2005 y Aldunate 2009).

\section{2.) LA EQUíVOCA PRÁCTICA DE LOS TRIBUNALES CHILENOS}

En una notable sentencia de la Corte Suprema, de fines de 1895, es posible encontrar una estupenda síntesis de la doctrina que ha predominado durante los siglos XIX y XX: "las disposiciones [las legales del caso, MNP] deben entenderse conforme con la Constitución del Estado, desde que se hayan consignado esplícitamente en leyes emanadas del poder público competente para dictarlas, i cuando no es posible discutir ni suponer que el lejislador ha violado la Constitucion, desde que los Tribunales no tienen facultad para declarar que las leyes dictadas en la forma prescrita por la Constitución, no deben ser aplicadas por juzgarlas inconstitucionales" 45

La doctrina recién transcrita ha disfrutado de estupenda salud durante todo el siglo XX y bien puede ser acompañada de numerosos ejemplos que, durante la vigencia de la Constitución de 1980, negaron expresamente la posibilidad judicial de desaplicar un precepto inconstitucional. Lo anterior, tanto antes ${ }^{46}$ como después ${ }^{47}$ de la reforma constitucional de 2005.

Con todo, al igual que acontece con la doctrina, hay notables y recientes excepciones dignas de ser destacadas.

A pocos meses de entrada en vigor la reforma de la Ley núm. 20.050, la Tercera Sala de la Corte Suprema conoció de un caso sobre la aplicación del artículo 54 de la Ley núm. 19.880, que establece que "[p]lanteada la reclamación [administrativa] se interrumpirá el plazo para ejercer la acción jurisdiccional”. Resolviendo los efectos de esta norma frente a la

45 Corte Suprema, sentencia de 11 de octubre de 1895, en Gaceta de los Tribunales, año LV (30 de noviembre de 1895), p. 773, cursivas añadidas. Véase el notable voto disidente del ministro Carlos Risopatrón.

46 Corte Suprema, rol núm. 6.957-95, 28 de diciembre de 1995, cons. $3^{\circ}$, en Gaceta Jurídica 445, pp. 1781-1784.

47 Véanse en este sentido una reciente sentencia de la Corte Suprema, 7 de septiembre de 2010, rol núm. 6212-2006, cons. $22^{\circ}$, y sentencia de la Corte Suprema, 13 de julio de 2011 , rol $4307-2009$, cons. $10^{\circ}$ y ss. 
acción constitucional de protección, en Thunderbird Antofagasta S.A. con Superindentencia de Casinos, la Corte Suprema estimó que la regla del artículo 54 no se aplica al plazo para deducir la acción de protección: "es lo cierto, que la norma del artículo 54 aludida se encuentra en completa contradicción con el artículo 20 de la Constitución Política de la República" ${ }^{8}$. Más adelante el fallo añade que "en caso alguno puede considerarse que la interposición de que habla el artículo 54 de la acción jurisdiccional, esté referida al recurso de protección porque precisamente el artículo 20 de la Carta Fundamental se anticipó a declarar que esta acción es sin perjuicio de otros derechos e implícitamente prohibió a la ley, norma de rango inferior, colocar cortapisas al pleno ejercicio de este arbitrio" (cons. $13^{\circ}$ ).

En Thunderbird se hace explícita la existencia de una contradicción entre una norma constitucional y una de rango legal, por lo que podría pensarse que la norma en cuestión ofrece problemas de validez. Sin embargo, si se examina con algo más de profundidad el razonamiento, es posible entender (más allá de las posibles críticas a esta sentencia) ${ }^{49}$ que la sentencia solo entiende que la norma no se aplica frente al plazo para recurrir de protección. En efecto, a diferencia de lo que acontece con la derogación tácita o la antinomia absoluta, la interpretación que el falloThunderbird propone del artículo 54 solo afecta su aplicación frente a una acción procesal constitucional determinada. Para el resto de las acciones procesales (por lo menos las de rango simplemente legal), el artículo 54 seguiría siendo una norma aplicable. Luego, y teniendo presente que una norma o es válida o inválida (no hay términos intermedios), lo que hace el fallo es orientar la aplicación de la norma, más que pronunciarse sobre su validez.

En un plano más frontal que Thunderbird se encuentran aquellas sentencias que derechamente afirman la existencia de antinomias entre las leyes y la Constitución o, por lo menos, fallan sin aplicar aquellas normas que consideran inconstitucionales. Entre estos casos se cuentan la declaración judicial de derogación que elimina la antinomia, constatando la pérdida de vigor de una norma (que fue válidamente producida) a raíz de la entrada en vigor de la Constitución, y las decisiones que, juzgando un acto de aplicación de la ley, (i) afirman como obiter dictum la competencia de todos los tribunales para apreciar las antinomias entre las leyes y la Constitución, o (ii) renuncian a cualquier vía que permita evitar la constatación de la contradicción con la Carta fundamental y afirman directamente la contradicción entre la Constitución y la ley.

Corte Suprema, 31 de mayo de 2006, rol núm. 1714-2006, cons. 6º cursivas ańadidas. En contra véase recientemente, de la misma Sala, el fallo de 24 de agosto de 2012, rol núm. 4605-2012.

49 Para una visión crítica véase el estudio de Ferrada (2006). 
Como ejemplo relevante de obiter dictum puede citarse un fallo de la Segunda Sala de la Corte Suprema que, no obstante desechar la tesis de la inconstitucionalidad o derogación del art. 450 del Código Penal, defiende fuertemente la tesis de la competencia judicial para constatar la derogación: "incumbe a todo Juez de la República la aplicación del ordenamiento jurídico a los casos concretos sometidos a su decisión. La integralidad y coherencia de dicho sistema de normas obliga al juzgador a elegir la norma o grupo de normas precisas que utilizará y el sentido de las mismas. En el ejercicio de esa labor intelectual de selección e interpretación puede identificar reglas jurídicas que contienen sentidos opuestos, e incluso reglas jurídicas que se oponen a sendos principios rectores del sistema jurídico. Pues bien, la solución de tales conflictos de normas es también objeto del juzgamiento. No se discute, en la doctrina constitucional, que los jueces del fondo tengan facultades para interpretar las reglas legales conforme a la Constitución, asi como tampoco la utilización de las normas constitucionales de un modo directo para la solución del conflicto específico y, en ambos casos, el juez ha debido interpretar la Constitución (...) Del mismo modo, es de competencia de los jueces del fondo el determinar la vigencia de una regla jurídica, ante la existencia de normas posteriores de contenido opuesto, sea que esa norma posterior tenga rango legal o constitucional. No altera el aserto precedente la modificación de nuestra Carta Fundamental, efectuada con ocasión de la Ley $N^{\circ} 20.050$ de 25 de agosto de 2005. En efecto, el inciso undécimo del artículo 93 de la Constitución Política de la República no prohibe una actuación de esa indole y solo contiene una facultad para el juez que conoce del asunto, en el sentido de elevar la consulta al Tribunal Constitucional, en caso de duda relativa a la inaplicabilidad de un precepto legal cuya aplicación resulte contraria a la Constitución" 50 .

El fallo recién citado circuló con rapidez en el foro, fue conocido y citado en el Tribunal Constitucional ${ }^{51}$ y despertó diversas inquietudes entre los observadores de la jurisprudencia constitucional.

Entre las decisiones de la judicatura ordinaria que afirman derechamente la inconstitucionalidad de normas legales cabe destacar el caso de varias sentencias dictadas en recursos de protección enderezados contra la supresión administrativa de cargos en las plantas de las universidades estatales. Entre diversos pronunciamientos de la Corte de Apelaciones de Santiago ${ }^{52}$, cabe destacar Vilches Moraga (sentencia de 4 de mayo de

Corte Suprema, 26 de noviembre de 2008, rol núm. 5420-2008.

Véase el voto de la ministra Peña, STC rol núm. 991 (29 de enero de 2009).

Véanse, a título de ejemplo, Corte de Apelaciones de Santiago, 14 de septiembre de 1992, rol núm. 4.198-92, Ln. 20.066; Corte de Apelaciones de Temuco, 4 de noviembre de 1992, rol núm. 732-92 (confirmada por la Corte Suprema, 23 de noviembre de 1992), Ln. 12.076; Corte de Apelaciones de Santiago, 2 de mayo de 1995, GJ. 180 (1995), 49 y ss.; Corte de Apelaciones de Santiago, 3 de enero de 1996, GJ. 197 (1996), 39 y ss.; y Corte 
1995): “[p]or pugnar el sentido que el rector viene dando al artículo 12 letra h), con el significado más propio del artículo $62 \mathrm{~N}^{\circ} 2$ de la Carta Primera, entiende la Corte que no es esa disposición, así asumida, una que se conforme con aquella. Surge, entonces, el supremo marco regulador de los artículos 5, 6 y 7 de esa Carta, que constriñe al juez al momento de desentrañar las fuentes de la decisión justa" ${ }^{" 3}$. No deja de llamar la atención el hecho que preceptos de idéntica naturaleza a los objetados en Vilches Moraga hubiesen aprobado posteriormente el test "concreto" de la inaplicabilidad bajo la Constitución reformada de $2005^{54}$.

Otro ejemplo, igualmente de interesante por su contraste con la jurisprudencia posterior del Tribunal Constitucional, es el que ofrece Leighton Araya, la sentencia de la Corte de Santiago, rol núm. 70.837 de 7 de diciembre de $2001^{55}$ que revocó una sentencia condenatoria en atención a que la ley delegatoria no había concedido autorización al Presidente de la República para dictar disposiciones penales relativas a la sustracción de energía eléctrica: " 6 ) Que, como puede advertirse de la simple lectura de esta ley delegatoria de facultades legislativas, no se concedió autorización al Presidente de la República para dictar disposiciones penales relativas a la sustracción de energía eléctrica y al contemplar ese tipo de normas aquél se excedió en el empleo de la función legislativa que recibió del Parlamento, lo que importa un vicio de ilegalidad que debe ser declarado de oficio, dejándose, por ende, de aplicar la norma".

El razonamiento de Leighton Araya contradice lo resuelto años más tarde por el Tribunal Constitucional, que "considerando la larga tradición histórica de los decretos con fuerza de ley" sostuvo "que las disposiciones contempladas en dichos cuerpos normativos dictados con anterioridad a la Constitución de 1980 no contradicen necesariamente la misma y siguen vigentes, no obstante comprender materias que de acuerdo al nuevo texto fundamental no pueden ser reguladas sino mediante normas legales, mientras no lesionen los derechos y libertades fundamentales que ésta re-

Suprema, 20 de marzo de 1996, RDJ. XCIII/1, secc. 2a. V., 51 y ss. (con jurisprudencia anotada).

53 Corte de Apelaciones de Santiago, 4 de mayo de 1995, FM. 439, 559 y ss., cons. $8^{\circ}$. Este fallo fue confirmado por la Corte Suprema, 8 de junio de 1995 .

54 "Que, conforme a lo razonado en los considerandos que anteceden, debe concluirse que no resulta contrario a la Constitución que el legislador confiera atribuciones de reestructuración orgánica a la autoridad de que se trata, atendidas las particulares características de autonomía que exige la administración de la Universidad de Chile, y que la eventual supresión de empleos que ella ocasione ha tenido suficiente origen en la voluntad del legislador, por lo que debe estimarse que, en caso de aplicarse en la gestión pendiente el precepto contenido en la letra h) del artículo 12 del Decreto con Fuerza de Ley 153, de 1981, ya transcrito, no producirá efectos contrarios a la Constitución”, STC rol núm. 523, 19 de junio de 2007, cons. $39^{\circ}$.

55 Un criterio similar a Leighton Araya aparece después como disidencia en el fallo de la Corte de Santiago, 31 de julio de 2007, rol núm. 29428-2004. 
conoce en sus aspectos materiales o concretos (...) aceptar una tesis contraria conllevaría indudables perjuicios al sistema jurídico y consecuentemente a la paz social, al cuestionarse per se relevantes materias reguladas en el pasado mediante decretos con fuerza de ley, otorgándole en materias formales o sustantivas a la actual Constitución un carácter retroactivo" 56 .

\section{5) DESAPLICACIÓN E INAPLICABILIDAD: EL ACTUAL CARÁCTER CON- CRETO DE LA INAPLICABILIDAD NO ES COMPATIBLE CON SU PRE- TENDIDO CARÁCTER MONOPÓLICO}

La cuestión que corresponde plantear es la siguiente: ¿es todavía posible encontrar algún sentido a las decisiones y a la doctrina minoritaria que defiende la capacidad de los jueces no constitucionales para dar aplicación a la Constitución? Dicho de otro modo, los casos de desaplicación que se han reseñado más arriba, ¿son, además de excepcionales, razonamientos judiciales patológicos? Y por lo que se refiere a la doctrina que, desde Luis Claro Solar en adelante, defiende la capacidad de los jueces para preferir la aplicación de la Constitución sobre las leyes inconstitucionales, ¿es posible cerrar la discusión afirmando solamente que se trata de una doctrina minoritaria y que la fuerza normativa de la Constitución se limita por el reparto de competencias que hace el artículo 93?

A mi juicio, la evolución que ha desarrollado la declaración de inaplicabilidad tras la reforma de la Ley núm. 20.050 agrega algo más que nuevas razones para volver sobre la discusión de esas capacidades judiciales y sobre el difuso concepto de control difuso de las leyes. En este sentido la tesis que aquí se sostiene es que no es posible defender, al mismo tiempo, el carácter concreto del juicio de inaplicabilidad y su condición de atributo monopolizado en manos del Tribunal Constitucional. Para sostener esta proposición me baso en un argumento distinto al que propuso Martínez Estay poco después de la reforma de 2005 (cual era el hecho que el artículo 93.6 parece conceder una facultad a los jueces, de modo que si los jueces están ciertos de la contradicción pueden no aplicar la norma inferior, Martínez 2005, pp. 465 y ss.). En mi opinión, lo fundamental no reposa tanto en el cambio de la redacción del instituto de la inaplicabilidad (donde mucho pudo haber de improvisación), sino en el modo en que el Tribunal ha venido concibiendo y construyendo la declaración de inaplicabilidad.

Como se sabe, hasta la reforma del año 2005 la visión oficial o "canónica" (en la terminología de Atria 2001) concibió el juicio de inaplicabilidad como la consecuencia de un razonamiento abstracto que consistía 
en comparar enunciados normativos. Esto condujo a que en numerosas sentencias la Corte Suprema afirmara que su función consistía en comparar textos y concluir si el precepto legal (es decir, la norma inferior) era o no contrario a la Constitución. Aunque este carácter "abstracto o doctrinario" 57 , en su desapego a los hechos, ha sido discutido por la doctrina (Atria 2001 y Aldunate 2008, pp. 11 y ss.) y contradicho históricamente por la propia jurisprudencia de la Corte Suprema ${ }^{58}$, lo cierto es que la jurisprudencia mayoritaria procedía a razonar a través de la comparación de textos. Como lo repitió tantas veces la Corte Suprema, la inaplicabilidad era un recurso "estrictamente jurídico"59 o "ajeno a toda consideración o resolución sobre cuestiones de hecho" ${ }^{60}$, que perseguía identificar una contradicción "directa"61, "completa y perfecta"62 entre normas a través de un "simple estudio de derecho" 63 o de "la confrontación de textos" 64 .

Concebida de este modo la declaración de inaplicabilidad y asociada a la superintendencia directiva, correccional y económica a que se refería el antiguo artículo 79 de la Constitución (que en teoría ordenaba y unificaba la jurisprudencia de todos los tribunales sujetos a ella) ${ }^{65}$, tenía algún sentido predicar el monopolio de la declaración de inaplicabilidad en la

Corte Suprema, 23 de septiembre de 1961, Revista de Derecho y Jurisprudencia LVIII 2a.1a., p. 357.

58 Véanse, entre otros, los fallos de la Corte Suprema de 13 de septiembre de 1931, De Castro, Revista de Derecho y Jurisprudencia XXX 2a.1a., pp. 36 y ss. (que da cuenta de cierta tendencia que hacía comprender que la inaplicabilidad procedía cuando había ofensa a los derechos de los particulares); 22 de septiembre de 1950, Pilassi, Revista de Derecho y Jurisprudencia XLVII 2a.1a., pp. 411 y ss.; 6 de mayo de 1964, Krsanac, Revista de Derecho y Jurisprudencia LXI 2a.1a., pp. 81 y ss.; 28 de enero de 1992, Duhart, Revista de Derecho y Jurisprudencia LXXXIX 2a.5a., pp. 15 y ss.; 9 de septiembre de 1992, Empresa Nacional de Electricidad S.A., Revista de Derecho y Jurisprudencia LXXXIX 2a.5a., pp. 254 y ss.; 24 de septiembre de 1993, Rojas, Gaceta Jurídica 159, pp. 49 y ss.; 6 de diciembre de 1996, Ravanal, Gaceta Jurídica 198, pp. 152 y ss.; y 24 de enero de 1997, Sociedad Agrícola, Ganadera y Forestal Covadonga Ltda., Revista de Derecho y Jurisprudencia XCIV 2a.5a., pp. 83 y ss.

59 Corte Suprema. 31 de marzo de 1995, Compañia Minera Tamaya, Gaceta Jurídica 181, pp. 164 y ss.

60 Corte Suprema, 31 de enero de 1986, Cortés, Revista de Derecho y Jurisprudencia LXXXIII 2a.5a., p. 7.

61 Corte Suprema, 4 de septiembre de 1963, Socovem Ltda., Revista de Derecho y Jurisprudencia LX 2a.1a., p. 247.

62 Corte Suprema, 21 de enero de 2004, Barría, Gaceta Jurídica 283, pp. 41 y ss.

63 Corte Suprema, 6 de diciembre de 1996, Labarca, Gaceta Jurídica 199, pp. 197 y ss.

64 Corte Suprema, 5 de agosto de 1948, Hott, Revista de Derecho y Jurisprudencia XLV 2a.1a., p. 677.

65 Recuérdese que durante la vigencia de la ordenación anterior a la Ley núm. 20.050, hubo jurisprudencia que indicó que "la admisibilidad del recurso de inaplicabilidad se encuentra subordinada a la circunstancia de que éste se haga valer en una gestión seguida ente otro Tribunal de la República sobre el cual la Corte Suprema puede ejercer superintendencia", Corte Suprema, 18 de agosto de 1993, cons. 2², Gaceta Jurídica 417, pp. 605 y ss. 
Corte Suprema. En otras palabras, para decirlo al modo germánico, existiendo conexión entre el guardián de la Constitución y todos los órganos que desde él descienden en la pirámide judicial era factible no solo que se velase por la atribución del superior, sino también porque los inferiores guardasen fidelidad hacia el modo en que el superior comprendía o interpretaba la Constitución. La inaplicabilidad tenía en cierto modo un sentido nomofiláctico y centralizador que emparentaba dicho instituto procesal con la casación. Y aunque se sabe que esto no siempre fue así, lo que para efectos del presente estudio importa es solamente la consistencia entre la pretensión del monopolio y la estructura orgánica en que ella se incardinaba: la inaplicabilidad era una expresión de poder del tribunal superior sobre los jueces inferiores.

Aunque se ha sostenido que la intención de la reforma de la Ley núm. 20.050 fue precisamente centralizar el control represivo en manos del Tribunal Constitucional, es posible demostrar que la obra que resultó tras la reforma y, particularmente, tras la comprensión de que de ella hizo el propio Tribunal no tuvo correspondencia con esa intención. Así, no es la presunta intención del constituyente, sino el análisis del modo en que el Tribunal ha comprendido y ejercido su competencia lo que permite entender qué hay y qué no hay de monopólico en el ejercicio de sus competencias. Esto último solo se entiende analizando el cambio de eje entre la vieja y la nueva inaplicabilidad (desde la formulación hacia la aplicación de la ley) y, dentro de ese cambio, las vías que utiliza el Tribunal para analizar los efectos que un precepto legal puede producir en una gestión judicial. Como se demuestra a continuación, dos de esas vías -la intervención sobre el proceso de interpretación conforme y sobre el proceso de identificación del campo de aplicación de la ley corresponden a la tarea ordinaria de cualquier juez y por lo tanto difícilmente pueden calificarse de atributos monopólicos de la jurisdicción constitucional.

\section{1.) El DESPlaZAMIENTO DEL JUICIO DE INAPLICABILIDAD HACIA LA REVISIÓN DE LA APLICACIÓN LEY}

Con la Ley núm. 20.050, el traslado de la competencia para conocer de la inaplicabilidad, desde la Corte y hacia el Tribunal Constitucional, produjo un efecto doblemente dramático. Por una parte, desapareció la conexión (o esa suerte de cordón umbilical que articulaba el antiguo artículo 79) entre los operadores judiciales y el "supremo" intérprete de la Constitución ${ }^{66}$ de modo que ni existe forma de controlar la pretensión de

66 Responsable de la "interpretación definitiva e inapelable de la Constitución", según lo entiende el Tribunal en la STC rol núm. 591 de 11 de enero de 1007, cons. $3^{\circ}$; véase también el voto del ministro Venegas en la STC rol núm. 1005, 24 de diciembre de 2007, ap. $1^{\circ}$. 
exclusividad 67 , ni modo de acreditar que el Tribunal sea tan "supremo" o incluso tan "especializado" 68 en la interpretación de la Constitución como lo sostiene su autopercepción. Por otra parte, y aquí radica el nudo de la cuestión, a partir del año 2006 el Tribunal comienza a construir un modo de entender la inaplicabilidad que, antes que clausurar una competencia, abre las puertas a la apropiación de las atribuciones jurisdiccionales de los jueces a quo. Es decir, a diferencia de lo que acontecía antes de la reforma donde los inferiores salían, aparente o realmente, al paso de las atribuciones del superior, la transformación de la inaplicabilidad ha hecho que sea el Tribunal Constitucional el que salga al encuentro de las atribuciones de los jueces ordinarios (de "estrados y mesón" en la terminología de Zúñiga 2010a, p. 136). Este salto hacia lo que es propio de la jurisdicción se produce con la comprensión que el Tribunal hace del control concreto de constitucionalidad.

La construcción del modelo concreto, de parte del Tribunal Constitucional, aunque es problemática no es accidental. Ella se fundamenta a partir del cambio de redacción introducido por la reforma de 2005, en aquella parte en que reemplazó el giro "precepto legal contrario a la Constitución" por "precepto legal cuya aplicación (...) resulte contraria a la Constitución". Sobre esa base el Tribunal construye una versión vernácula de su competencia que consiste, por una parte, en considerar como impropia la revisión en abstracto de la norma y, por otra, en entender que lo propio de la inaplicabilidad consiste en "determinar si aplicación del precepto en la gestión específica resulta contraria a la Constitución"69. Esta última percepción se resume en un fallo en el que el Tribunal hace propias las palabras del profesor porteño Lautaro Ríos: "la magistratura constitucional no está compelida a la mera comparación abstracta de dos normas de diverso rango (...) sino que en el instituto de la inaplicabilidad por inconstitucionalidad 'comparecen tres elementos de cotejo necesarios para su decisión; a saber: la norma constitucional, el precepto legal cuya inaplicación se solicita $y$-lo más especificamente decisivo- el examen particular acerca de si, en ese caso, la aplicación del precepto cuestionado pudiera generar efectos opuestos a la finalidad implicita de aquella...'. Por eso, 'puede advertirse que hay preceptos legales que pueden estar en perfecta consonancia con la carta fundamental y, no obstante ello, ser inaplicables a un caso par-

Sobre esta pretensión véase la STC rol núm. 597 (4 de septiembre de 2007), voto de los ministros Fernández Baeza y Correa Sutil.

68 STC rol núm. 591, 11 de enero de 2007 , cons. $12^{\circ}$. Sobre las dificultades que enfrenta la supremacía interpretativa del Tribunal en sede de inaplicabilidad, véase SiLva (2012), pp. 588 y ss.

69 STC rol núm. 480, 27 de junio de 2006 , cons. $27^{\circ}$. Esta versión local de instituto, centrado en los efectos de la aplicación de un precepto (que puede ser perfectamente constitucional) $\mathrm{y}$ con efectos inter partes no hace fácil su equivalencia con otras expresiones comparadas de control concreto 
ticular, precisamente porque en la particularidad de ese caso, la aplicación de una norma legal objetada es contraria a los efectos previstos por la norma constitucional" 70 . Como en este lugar no es posible profundizar la incidencia de esta forma de control sobre la revisión de sentencias judiciales (Pica 2010), solo cabe reiterar que, en palabras del propio Tribunal, a la inaplicabilidad no corresponde un examen abstracto (texto contra texto, como decía la Corte Suprema), sino uno concreto, anclado en las particularidades de un caso. Las particularidades de este caso (i) impiden, en concepto del mismo Tribunal, extraer consecuencias generales o universales desde sus razonamientos, (ii) obligan al requirente a prodigar la mayor cantidad de información factual posible, $y$, en fin, (iii) explican que un precepto pueda ser considerado constitucional en abstracto $y$, aplicado en un caso concreto, considerado como la causa de la infracción de la Constitución.

La diferencia con el modelo anterior salta a la vista. En los casos paradigmáticos del viejo modelo (ya se ha dicho que hubo excepciones, como también las hay con el modelo actual) el proceso de inaplicabilidad presuponía una antinomia y, por lo tanto, un juicio (débil, por sus efectos relativos, pero juicio al fin y al cabo) sobre la validez de la norma. El modelo actual, en cambio, solo exige que los resultados de la aplicación de una norma (y no ella en sí misma) sean contrarios a la Constitución, por lo que de juicio sobre normas la inaplicabilidad pasa a transformarse en juicio sobre aplicación de normas. Cabe advertir que ello no significa que en la inaplicabilidad sea completamente imposible sostener que la ley, además de aplicada en ese caso, puede ser siempre y en todo lugar inconstitucional (esto es el facial challenge del que hablan los estadounidenses) ${ }^{71}$, como tampoco significa que el Tribunal sea enteramente coherente con este carácter concreto y con la pretendida relevancia de los hechos (a veces, señala un autor, "la referencia al carácter concreto del control es simple anuncio de lo que el Tribunal no hace", Aldunate 2009 , p. 15). Sí en cambio significa que dadas ciertas circunstancias el ejercicio de la jurisdicción constitucional, vía de inaplicabilidad, puede acercarse mucho al ejercicio de la jurisdicción ordinaria (demostrando con ello la existencia de competencias concurrentes).

Algunas de las circunstancias que pueden acercar la inaplicabilidad, como juicio sobre la aplicación de la ley, al ejercicio de la jurisdicción ordinaria han sido expresamente previstas y excluidas por el Tribunal. Entre otras pueden ser mencionadas: (i) el pronunciamiento sobre la vi- 
gencia de las leyes en el tiempo ${ }^{72}$, (ii) los juicios sobre legalidad ${ }^{73}$, (iii) el juicio sobre la existencia de unos hechos "sustanciales, pertinentes y controvertidos"74, (iv) la calificación jurídico-penal de unos hechos ${ }^{75}$, y (v) la identificación de los preceptos conforme a los cuales debe ser resuelta una determinada gestión ${ }^{76}$. Mediante la identificación, ciertamente casuista, de todas estas circunstancias el Tribunal ha procurado no apropiarse de las funciones que corresponden a los jueces de la gestión.

Con todo, en el campo de la inaplicabilidad existen al menos dos áreas vastas y relevantes respecto de las que el Tribunal no renuncia, pero de la cuales no puede pretender exclusividad: el control de la interpretación y de la definición del campo de aplicación de la ley. Esas áreas surgen, entonces, como campos necesariamente yuxtapuestos de la inaplicabilidad y de la jurisdicción ordinaria.

\section{2.) LA CAPACIDAD DEL TRIBUNAL PARA INTERVENIR SOBRE LOS PROCESOS DE INTERPRETACIÓN DE LA LEY: LA INTERPRETACIÓN CONFORME}

Aunque en algunas sentencias el Tribunal ha declarado formalmente que la interpretación de la ley es una atribución más de los jueces de la gestión que limita la competencia de esa Magistratura ${ }^{77}$, lo cierto es que en una buena parte de procesos el mismo Tribunal se ha avocado a revisar los modos de interpretación de la ley. Toda la construcción de la "interpretación conforme" en sede de inaplicabilidad, implícita o explícita en fallos emblemáticos como Isapres, Hopp, Reyes Kokish, los casos sobre la aplicación del artículo 2331 del Código Civil o sobre la investigación de la paternidad, se justifican precisamente en la imposibilidad de separar los procesos de aplicación de los de interpretación. Como señaló en la sentencia rol núm. 480 (27 de julio de 2006): ["1]o que el Tribunal debe

72 SSTC roles núm. 503, 19 de julio de 2006, cons. $9^{\circ} ; 513,2$ de enero de 2007 , cons. $7^{\circ}$; 796,11 de diciembre de 2007 , cons. $7^{\circ}$; 976,26 de junio de 2008 , cons. $16^{\circ}$; y 1532,24 de agosto de 2010 , cons. $7^{\circ}$.

73 SSTC rol núm. 480, 27 de junio de 2006, cons. 32º ;úm. 790, 11 de diciembre de 2007, cons. $28^{\circ}$; num. 796,11 de diciembre de 2007 , cons. $27^{\circ}$.

74 STC rol núm. 806, 11 de diciembre de 2007, cons. $28^{\circ}$.

75 STC rol núm. 549, 30 de marzo de 2007, cons. $9^{\circ}$.

76 STC rol, núm. 806, 11 de diciembre de 2007, cons. $5^{\circ}$.

77 "La tarea de interpretar la ley le corresponde a los tribunales de justicia, sean ordinarios o especiales, y, en nuestro sistema judicial, el órgano llamado a unificar su interpretación es la Corte Suprema, a través del recurso de casación. La labor del Tribunal Constitucional consiste en velar por el respeto del principio de supremacía constitucional y, por ende, tratándose de una acción de esta clase, resolver si la aplicación en el caso concreto de que se trate del precepto legal impugnado, resulta o no contraria a la Carta Fundamental y, como efecto natural de una decisión estimatoria, prohibir al juez de la causa aplicarlo en la resolución de ese caso concreto", STC rol núm. 810, 24 de enero de 2008, cons. $9^{\circ}$. 
practicar es un examen concreto de si el precepto legal, invocado en una gestión judicial pendiente y correctamente interpretado producirá efectos o resultados contrarios a la Constitución" (cons. $\left.27^{\circ}\right)^{78}$; dicho de otro modo: "no cabe pronunciarse por la inconstitucionalidad de una norma (en la especie, por la inaplicabilidad de ella) si la misma admite, correctamente interpretada, una lectura conforme a la Carta Fundamental"79. Siendo posible la interpretación conforme, el Tribunal no renuncia a pronunciarse sobre lo debatido, aunque sea a través de una sentencia desestimatoria interpretativa, como sucedió en los casos $H o p p^{80}$ y Morri$s o n^{81}$. Con ello, el Tribunal hace de la interpretación conforme un objeto posible de la inaplicabilidad y, por lo tanto, emparenta una competencia propia de los tribunales ordinarios con el ejercicio de una atribución que en principio le parecía exclusiva. En efecto, si conforme con la letra de la Constitución, el control es uno de aplicación y esta última es virtualmente inseparable de la interpretación, entonces el control lo es también del proceso de interpretación. La pertinencia de la reflexión hace inevitable la siguiente cita: "hay que subrayar la relación entre interpretación y aplicación, que no es una conjunción ocasional sino un nexo de inescindibilidad: que en el Derecho no haya aplicación sin interpretación puede resultar claro, hasta banal; menos claro, pero por otra parte verdadero, es el inverso: que no hay interpretación sin aplicación. La esencia del Derecho está en este nexo, en el cual se manifiesta su valor práctico" (Zagrebelsky 2008, p. 161).

La inseparable relación entre aplicación e interpretación se encuentra también descrita en los anales de nuestra jurisprudencia constitucional, específicamente en el notable voto disidente que el ministro Correa Sutil hace constar en el fallo Boronig: "es físicamente imposible que una ley pueda producir, por sí sola, un efecto contrario a la Constitución en una gestión determinada (...) Siempre que el precepto legal produzca efectos en un caso, lo será porque el juez le ha dado aplicación y para darle aplicación debe fijar su sentido y alcance. En razón de ello, cuando el efecto contrario a la Carta Fundamental es producido por la interpretación del juez, esta Magistratura igualmente debe conocer. (...) Los preceptos legales que los jueces deben interpretar y aplicar, se formulan a través de un lenguaje y ese lenguaje no significa nada si no es para quien lo descifra, para quien fija su sentido y alcance, usando para ello las convenciones propias de la semántica y sintáctica del idioma respectivo y recurriendo a los demás elementos de interpretación. Si un juez fija un sentido y alcan- 
ce razonable y posible de un precepto legal y, aplicado en ese sentido el precepto legal al caso, produce efectos contrarios a la Carta Fundamental, es deber de esta Magistratura evitarlo" 82 .

\section{3.) LA CAPACIDAD DEL TRIBUNAL PARA INTERVENIR SOBRE LOS PROCESOS DE INTERPRETACIÓN DE LA LEY: EL CONTROL SOBRE EL ÁMBITO DE APLICACIÓN DE LAS LEYES}

Otra hipótesis vinculada con la interpretación y que, por lo tanto, el Tribunal ha considerado como parte de la revisión de la constitucionalidad de la aplicación de una ley es la revisión de la concordancia entre los hechos del juicio y el supuesto normativo de una ley. Esta práctica queda en evidencia en la STC rol núm. 707 (25 de octubre de 2007) ${ }^{83}$, cuyo cons. $13^{\circ}$ estima que el procedimiento que crea el DL núm. 2.695 "en su aplicación concreta al caso (...) resulta contrario a la Constitución, pues significaria resolver un conflicto sobre posesión y dominio de bienes raices rurales de acuerdo con normas legales (...) diversas a las disposiciones generales contenidas en el Código Civil, sin que, a juicio de este Tribunal, concurran en la especie los motivos que justifican la aplicación de aquellas normas especiales, las cuales, en caso de ser utilizadas, constituirian una diferencia arbitraria y podrian dar origen a una privación inconstitucional de la propiedad" (cursivas añadidas).

En el caso recién anotado, el Tribunal derechamente revisa si la norma se ha aplicado correctamente ratione materiae, porque la consecuencia de no serlo es la incompatibilidad con el principio de igualdad ante la ley. Un fenómeno parecido se advierte en decisiones posteriores que han abierto la discusión sobre si la inaplicabilidad puede ser considerada como una suerte de "amparo imperfecto" 84 . Si bien no es posible sostener que se trata de una modalidad de procesos unánimemente admitidos en nuestra praxis jurisprudencial -hay fallos que expresamente ha negado el presunto carácter de amparo de la inaplicabilidad ${ }^{85}$, el objeto tutelar de la inaplicabilidad se ha hecho evidente en procesos vinculados al examen de la corrección de la aplicación de la ley y su influencia sobre el ejercicio de los derechos que la Constitución asegura. Así, en la STC rol núm. 1145 (17 de marzo de 2009), el Tribunal acogió una inaplicabilidad respecto del artículo 238 del Código de Procedimiento Civil en relación con el inciso $2^{\circ}$ del artículo 32 de la Ley Orgánica Constitucional de Municipalidades: "el apremio dispuesto contra el Alcalde de Arauco en

\footnotetext{
82 STC rol núm. 810, 24 de enero de 2008, voto del ministro Correa, apdo. 3.

83 Sobre los alcances de este fallo para el desarrollo del control concreto, he adelantado opinión en NúÑEZ (2008), pp. 145 y ss.

84 Véanse Cazor y Pica (2009), Pfeffer (2011) y Zúñiga (2010b), p. 346.

85 Así por ejemplo, la STC rol núm. 1576, 16 de diciembre de 2010 , cons. $35^{\circ}$.
} 
la causa sub lite -y que se funda en las disposiciones legales reprochadas a través de esta acción de inaplicabilidad- siendo legítimo en su origen, ha devenido en ilegítimo, pues no aparece, en la actualidad, proporcionado a la consecución de un fin de interés social relacionado con la decisión de autoridad competente, en el marco de un proceso justo, en la medida que se mantiene vigente más allá del supuesto previsto en las normas legales tenidas en vista para decretarlo" 86 .

Más recientemente, la STC rol núm. 1615 (20 de enero de 2011), el Tribunal declaró con el voto en contra de los ministros Carmona y Navarro que "si bien -en teoría- la correcta interpretación de las normas en juego basta para establecer la procedencia del pago de la asignación profesional en este caso, lo concreto y real es que una decisión administrativa, que invoca el precitado artículo 35 de la Ley Orgánica Constitucional de Enseñanza, ha privado del beneficio a su titular, de suerte tal que esta Magistratura no puede ignorar que a dicha norma -fundándose en una cierta interpretación - se le ha dado aplicación para resolver la relación jurídica que sirve de base a este proceso. No existe una antinomia absoluta entre conflictos legales y constitucionales, en términos que unos y otros se excluyan siempre, porque la rica variedad del derecho admite -como en este caso- que la eventual preferencia de un precepto legal sobre otro involucre, en la regulación de una determinada situación jurídica, la privación de un derecho constitucional" (considerando $16^{\circ}$, cursivas añadidas). En este último fallo el Tribunal ofrece la clave explicativa de su competencia: la separación entre conflictos estrictamente legales y conflictos estrictamente constitucionales no es tajante, de modo que un tipo de conflicto no excluye necesariamente al otro. Por lo tanto, de ser correcto este proceder, el ejercicio de la competencia de inaplicabilidad en casos como los recién reseñados comparte necesariamente un espacio con la competencia general de los órganos jurisdiccionales. Y, por el contrario, la competencia general de los órganos jurisdiccionales comparte un área que es común a la jurisdicción de inaplicabilidad.

\section{4.) CONSIDERACIONES FINALES Y CONCLUSIONES: LO QUE PUEDE $Y$ NO PUEDE HABER DE MONOPÓLICO EN EL PROCESO DE INAPLI- CABILIDAD}

Llegado a este punto corresponde preguntarse si tiene sentido defender como parte de una competencia monopólica la jurisdicción del Tribunal Constitucional para participar de los procesos de interpretación inseparablemente asociados a la aplicación de la ley y descritos en las párrafos 
3 y 4 precedentes. Como se adelantó al principio de este apartado, la tesis que se sostiene en este ensayo responde con la negativa. Por el contrario, la única pretensión justificable de exclusividad sería la afirmación de una antinomia que solo pueda remediarse con la supresión o con la modificación del precepto legal. En efecto, si la esencia de la jurisdicción es la aplicación y esta presupone siempre la interpretación, no tiene sentido extirpar de esta última la capacidad de contrastar los sentidos atribuibles a un precepto legal con la propia Constitución. Si se quiere ser coherente con el principio de fuerza normativa de la Constitución, tantas veces declamado en la retórica constitucional, deberá concordarse en que todos los jueces están llamados a aplicar los preceptos legales del modo en que más conformes resulten con la Constitución, aun si con ello se apartan del estricto tenor literal de la ley. Defender lo contrario implica radicar en el Tribunal Constitucional la revisión de todas las formas jurisdiccionales de aplicación de la ley, transformando a este Tribunal en una suerte de tribunal de casación antes que en un guardián de la supremacía constitucional.

Por lo que se refiere a la revisión de la concurrencia de los supuestos normativos de una ley en un caso determinado, también es insostenible la tesis del monopolio, puesto que la identificación del campo o de los supuestos de aplicación de cualquier norma es parte de todo proceso de atribución de significado de las mismas. Se trata de procesos tan inseparables de la función de "decir el Derecho" que es imposible identificar solamente en ellos un atribución monopólica o exclusiva del Tribunal Constitucional. En este sentido, si se tratara solo de una interpretación sistemática de las normas, la exégesis del artículo 93.6 de la Constitución -en aquella parte en que se refiere a la "aplicación" - necesariamente debe tener en cuenta la inteligencia del artículo 76, que se refiere a la facultad de "conocer" y "resolver". En otras palabras, y sin necesidad de recurrir nuevamente al manido principio de la fuerza normativa de la Constitución, el sentido que debe atribuirse a la potestad de negar la aplicación de una ley (artículo 93.6 de la Constitución) no puede privar de su eficacia a otra potestad igualmente garantizada por la Constitución (artículo 76). Y como la afirmación inversa también es cierta, es decir, la interpretación del art. 76 no puede menoscabar el alcance del art. 93.6 de la Carta, es preciso entender que ambas atribuciones deben ejercerse conforme a un principio de lealtad constitucional, en virtud del cual, de haber declaración de inaplicabilidad, los jueces de la gestión no pueden desobedecer el contenido de la sentencia a pretexto de afirmar que lo que ella dice no les obliga.

Hay que hacer presente además que la propia jurisprudencia del Tribunal Constitucional da buenas razones para entender que los jueces están facultados y, en ciertos casos, obligados a dejar de aplicar preceptos 
legales (o sus equivalentes) o, por lo menos, a prescindir de su expreso tenor literal. Entre las razones que ofrece la jurisprudencia del Tribunal Constitucional se encuentran todas aquellas sentencias interpretativas dictadas en los procesos de control preventivo (obligatorio o facultativo), incluyendo las curiosas "declaraciones de esterilidad normativa" formuladas a propósito de ciertos instrumentos internacionales (a esta jurisprudencia me he referido anteriormente, vid. supra III.3). ¿Cómo entender estas declaraciones si no como autorizaciones o, más bien, instrucciones hacia los jueces en orden dejar de aplicar los preceptos legales o sus equivalentes sustanciales? En la propia jurisprudencia del Tribunal es posible identificar trazas sobre de la libertad interpretativa de los jueces y sus límites ${ }^{87}$, de donde se desprende lo obvio: dentro de los márgenes de la letra es el juez quien opta por los sentidos en función del caso.

Los medievales, y más atrás los filósofos griegos, se plantearon esta pregunta: ¿debe acatarse la ley justa? La respuesta, cuando la ley era justa en la letra pero injusta en su aplicación, era la siguiente: puede no aplicarse la ley, en cuyo caso se dice que cesa para el caso concreto pero mantiene su vigencia para lo demás. La explicación que dio a esta excepción de la autoridad de la ley no es compleja. Según el jesuita Suárez "la ley se da en general y es imposible que la disposición general de una ley humana resulte tan recta en todos los casos particulares que no falle alguna vez" (Suárez 1967, Libro IV.VI.4, p. 653). En la misma línea De Soto explicaba que "ciertamente la ley, según se ha dicho, se establece en común, porque no puede atender suficientemente a los casos particulares" (De Soto 1967, Libro I quastio VI, art. VIII, p 72). Este acto particular de

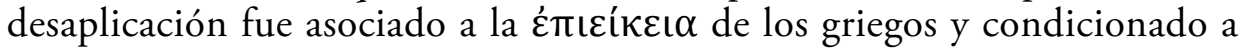
la injusticia de exigir el cumplimiento del precepto. No bastaba con que el precepto fuese injusto o difícil, lo central era la injusticia de su cumplimiento.

Luego, la pregunta por la capacidad del juez para no aplicar la ley no es nueva. Lo que hace el constitucionalismo racionalista es reemplazar el parámetro subjetivo de la justicia y de la "humanidad" 88 por uno más objetivable y democrático: la Constitución, pero mantiene buena parte de las afirmaciones y de las preguntas que formularon los antiguos: la desaplicación no afecta la validez universal de la ley, aunque no sea siempre fácil discernir si el juez puede decidir por sí mismo o si debe consultar al superior. Respondiendo a esta última cuestión, Schmitt sugirió que el juez tiene la facultad para no aplicar la norma legal si al mismo tiempo es capaz de subsumir la hipótesis en la norma constitucional. Dada esta últi-

\footnotetext{
87 Véase la STC rol núm. 1281, 13 de agosto de 2009., cons. $21^{\circ}$ y ss., con una interesante referencia a las posibilidades de interpretación amplia o restrictiva de las leyes penales. 
ma posibilidad, el juez está habilitado para aplicar la norma preferente sin emitir un juicio sobre la validez de la norma no aplicada y solo resolviendo la "falta de aplicación de la simple ley al caso concreto, que sobreviene por ser obligada la aplicación del precepto constitucional" 89 . Aunque esta tesis provenga del principal opositor a la idea de una jurisdicción constitucional especializada, ella no deja de ser esclarecedora. En efecto, antes de denegar a priori la capacidad judicial para desaplicar un precepto legal (véase recientemente el estudio nacional de Marshall 2010, pp. 51-52) y reenviar el problema al guardián de la Constitución, exige que el juez revise primeramente la posibilidad de subsumir el problema en la norma constitucional. Si esta subsunción es posible porque la cobertura de la norma constitucional es lo suficientemente precisa y no da margen a la opinión, el deber de sometimiento a la legalidad cede simplemente a favor del deber de sometimiento a una legalidad superior. Dicho de otro modo, la sumisión a la ley no excluye la sumisión hacia la Constitución, a condición que las respuestas que ofrezca esta última sean lo suficientemente precisas como para no albergar una variedad de respuestas contradictorias frente al mismo problema.

Comprendida en sede constitucional, la vieja fórmula de la corrección de la ley para el caso particular, se reemplaza por la competencia judicial ordinaria para aplicar la Constitución y/o corregir interpretativamente de la ley, que solo se detiene ante las antinomias insalvables, propias del control abstracto y que corresponde por razones de "buen orden" diría Suárez al consultar al superior. Ahora bien, tanto la negación de la aplicación de una norma por preferir la aplicación de otra, como la corrección de la significación de un precepto para ajustarlo en su interpretación a la Constitución, son procesos revisables por todos los recursos ordinarios y extraordinarios de la legislación procesal y están sujetos, si cabe, a la superintendencia directiva y correccional de la Corte Suprema. Entendidas así las cosas, la desaplicación no sería otra cosa que una manifestación del sentido más propio de la jurisdicción, que ajustado a las exigencias de certeza que se han insinuado más arriba, no necesariamente empujan al sistema hacia la sustitución del derecho legislado por el derecho judicial ${ }^{90}$.

Llegados a este punto, la conclusión que resta por hacerse explícita es el grado de exclusividad, y por lo tanto de monopolio, que podría haber en la declaración de inaplicabilidad. Y la tesis que se resume aquí es la siguiente: lo que sí puede considerarse como justificativo de la pretensión de exclusividad de parte del Tribunal Constitucional es la construcción de aquellas antinomias que a fin de cuentas afectan la validez de la ley.

\footnotetext{
89 SсHмiтt (1998), p. 48.

90 Díez-Picazo (1985), p. 22.
} 
La simple desaplicación (sin antinomia) y las hipótesis de aplicación directa de la Constitución por subsunción precisa del hecho en el texto constitucional (en presencia de antinomia) no forman parte del acervo de competencias exclusivas y excluyentes del Tribunal Constitucional. Las razones explicadas más arriba se refuerzan con dos ideas finales. En primer lugar, en la inaplicabilidad se advierte un sesgo que no se da en el resto de las hipótesis de desaplicación (consideremos provisoriamente que la inaplicabilidad es una hipótesis de desaplicación): solo la inaplicabilidad declarada por el Tribunal Constitucional sirve de único e imprescindible antecedente para la declaración de inconstitucionalidad (artículo 93.7 de la Constitución). La segunda idea se encuentra íntimamente ligada a la anterior y se refiere al sentido político-legislativo que las hipótesis cotidianas de desaplicación judicial no tienen. La inaplicabilidad, en la medida en que sirve de único antecedente para la declaración de inconstitucionalidad, constituye un germen de mensaje oficial al legislador: hay buenas razones para creer que la ley padece de un vicio y por tanto es conveniente que ella sea revisada. Este contenido político-legislativo de la sentencia, no pocas veces acompañado de admoniciones al legislador, no es propio de las jurisdicciones ordinarias o no constitucionales. Por el contrario, él sí es un privilegio de la jurisdicción constitucional especializada.

De lo dicho hasta aquí puede concluirse lo siguiente:

a) A partir de la entrada en vigor de la Ley núm. 20.050, en lo que a las atribuciones del Tribunal Constitucional se refiere, es posible discernir dos ámbitos expresos de competencia que permiten a los jueces desaplicar la ley sin romper el principio de sujeción del juez a la ley ni incurrir en conductas cercanas a la prevaricación. Estos dos ámbitos coexisten y se fundan, el uno, en la noción de jurisdicción que describe el art. $76 \mathrm{CPR}$, y el otro, en la capacidad para ordenar la inaplicabilidad de un precepto legal que el art. 93.6 concede al Tribunal Constitucional. Tras la reforma, ambas atribuciones se enriquecen y complementan recíprocamente.

b) Las dos potestades anteriormente señaladas deben coexistir y comprenderse en su justa medida. Así, la capacidad judicial para dejar sin aplicación un precepto legal no afecta la validez jurídica de esta y se fundamenta en diversas hipótesis que permiten la desaplicación en ausencia de antinomias o en presencia de las llamadas antinomias débiles o no invalidantes. Entre estas hipótesis pueden señalarse la desaplicación por un imperativo superior, la desaplicación por derogación, la desaplicación por la preferencia de la norma más favorable, la desaplicación por prevalencia de criterios interpretativos fijados por el propio Tribunal Constitucional y hasta por la interpretación axiológica del ordenamiento legal. 
c) Con relación a las antinomias invalidantes no hay acuerdo completo en la doctrina ni en la práctica, pero en la medida en que la inaplicabilidad funge de instrumento de control del ejercicio de la jurisdicción -con todos los procesos hermenéuticos que le son propios y no necesariamente de instrumento de control de la legislación, es que tampoco cabe duda que hay aspectos del juicio de inaplicabilidad -tales como el control del ámbito de aplicación de la ley o el pronunciamiento sobre el deber de interpretación conforme que son compartidos con la jurisdicción ordinaria. Dentro de este marco, las probabilidades de que el juez invada los dominios del Tribunal Constitucional son tan altas como las que el Tribunal interfiera en el ejercicio de las atribuciones que corresponden a los tribunales de la gestión. Por lo tanto, no es posible afirmar al mismo tiempo que la inaplicabilidad es un proceso de control concreto centrado en la aplicación y que ella es una competencia exclusiva del Tribunal Constitucional.

d) De acuerdo con lo anterior, lo que sí resulta exclusivo para el Tribunal es la incoación de un proceso llamado de inaplicabilidad, con la capacidad de suspender la gestión, de ordenar imperativamente -a través de una decisión dotada de la fuerza de cosa juzgada - la inaplicabilidad de un precepto legal y de sentar, por esa misma vía, las bases para una posible y futura declaración de inconstitucionalidad.

\section{BIBLIOGRAFÍA}

- Aedo, Cristian (2006), Responsabilidad extracontractual. Santiago de Chile: Librotecnia.

- Aldunate, Eduardo (2008), Jurisprudencia constitucional 20062008. Estudio selectivo (LegalPublishing, Santiago de Chile).

- Aldunate, Eduardo (2009), "La fuerza normativa de la Constitución y el sistema de fuentes del Derecho", Revista de Derecho de la Pontificia Universidad Católica de Valparaíso XXII, pp. 443-484.

- Alonso García, María (1995), "La inaplicación administrativa de reglamentos ilegales y leyes inconstitucionales", Revista de Administración Pública 138, pp. 203-223.

- Alonso García, Ricardo (2001), Las sentencias básicas del Tribunal de Justicia de las Comunidades Europeas. Madrid: BOE/Centro de Estudios Políticos y Constitucionales.

- Andrade, Carlos (1971), Elementos de Derecho constitucional chileno ( $2^{a}$ ed.). Santiago de Chile: Ed. Jurídica de Chile. 
- Atria, Fernando (2001), "Inaplicabilidad y coherencia: contra la ideología del legalismo", Revista de Derecho (Valdivia) 12/1, pp. 119156.

- BaChof, Otto (1994), Normas constitucionais inconstitucionais (trad. J. Cardoso da Costa, reimpr. de la ed. de 1977). Coimbra: Livraria Almedima.

- Ballesteros, Manuel (1890), La lei de organización y atribuciones de los tribunales de Chile. Santiago de Chile: Imprenta Nacional, tomo I.

- Barros, Enrique (2007), Tratado de responsabilidad extracontractual. Santiago de Chile: Editorial Jurídica de Chile.

- Bоввіо, Norberto (1993), Teoria generale del diritto. Torino: G. Giappichelli.

- Cançado, Antônio (2001), El Derecho internacional de los derechos humanos. Santiago de Chile: Ed. Jurídica de Chile.

- Carnelutti, Francesco (1961), Discorsi in torno al Diritto. Padova: Cedam, vol. III.

- Cazor, Kamel y Pica, Rodrigo (2009), "Tribunal Constitucional y control concreto en Chile: ¿evolución hacia un amparo imperfecto?”, Revista General de Derecho Constitucional (Iustel), 7.

- Cerda, Carlos (1992), Iuris Dictio. Santiago de Chile: Ed. Jurídica de Chile.

- Claro Solar, Luis (1934), "Los decretos leyes y el recurso de inaplicabilidad que establece el art. 86 de la Constitución", Revista de Derecho y Jurisprudencia XXXI, $1^{\text {a }}$ parte, pp. 13-18.

- Corng, Helmut (1961), Fundamentos de filosofía del Derecho (trad. J. Mauri). Barcelona: Ariel.

- Cordero, Eduardo (1995), La potestad reglamentaria en el Derecho público chileno (Memoria de prueba). Valparaíso: Universidad Católica de Valparaíso.

- Crisafulli, Vezio (1993), Lezioni di Diritto Costituzionale (6a ed., a cura di F. Crisafulli). Padova: Cedam.

- De Otтo, Ignacio (1988), Derecho constitucional. Sistema de fuentes. Barcelona: Ariel.

- De Soto, Domingo (1967), De iustitia et iure Libri Decem [1557] (trad. cast. M. González). Madrid: Instituto de Estudios Políticos, vol I.

- Díez-Picazo, Luis (1985), "Constitución, Ley, Juez", Revista Española de Derecho Constitucional 15, pp. 9-23.

- Dómenech, Gabriel (2007), "La inaplicación administrativa de reglamentos ilegales y leyes inconstitucionales", Revista de Administración Pública 155, pp. 59-106. 
- Domínguez, Carmen y Domínguez, Ramón (1991), "Lo que la jurisprudencia se llevó", Revista de Derecho (Universidad de Concepción) 189, pp. 95-110.

- Engisch, Karl (2001), Introducción al pensamiento jurídico [1956] (trad. E. Garzón). Granada: Comares.

- Fernández, Miguel A. (2005), "Constitución y casación: ¿de la falta de aplicación al monopolio constitucional?", Estudios Constitucionales 3/1, pp. 97-118.

- Fernández, Miguel Ángel (2001), "La fuerza normativa de la Constitución”, Revista de Derecho Público 63, pp. 77-102

- Ferrada, Juan Carlos (2006), "Comentario. La sentencia sobre interpretación del art. 54 LBPA que establece la interrupción de los plazos judiciales mientras se resuelven recursos administrativos interpuestos previamente", Revista de Derecho (Valdivia) 19/2, pp. 257-264.

- Ferrajoli, Luigi (2007), Principia iuiris. Teoria del diritto e della democracia. Roma-Bari: Laterza.

- Galecio, Rubén (1966), "El juez ante la crisis (1)", Revista de Derecho y Jurisprudencia LXIII/5, 1a., pp. 121-147.

- Gandulfo, Eduardo (2008), "Casación y Constitución, en materia de fondo civil. Reflexiones metodológicas sobre una sentencia que venció las tentaciones", Ius et Praxis 14/2, pp. 611-637.

- García de Enterría, Eduardo (1985), La Constitución como norma y el Tribunal Constitucional. Madrid: Civitas.

- Gascón, Marina (1994), "Cuestiones sobre la derogación”, Doxa 1516, pp. 845-859.

- Guzzetta, Giovanni (1994), Costituzione e regolamenti comunitari. Milano: Giuffrè.

- Henríquez, Miriam (2012), “¿Las normas derogadas pueden ser declaradas inaplicables por inconstitucionalidad?”, en Silva, María Pía y Henríquez, Miriam (coords.), Derechos fundamentales y justicia constitucional. ¿Consolidación o reforma? Santiago de Chile: Abeledo Perrot Thomson Reuters, pp. 197-208.

- Hunneus, Jorje (1880), La Constitución ante el Congreso o sea comentario positivo de la Constitución chilena. Santiago de Chile: Imprenta de Los Tiempos, vol. II.

- Kelsen, Hans (1995), Teoría pura del derecho [1960] (trad. R. Vernengo). México D.F.: Porrúa.

- Laubadère, André, Venezia Jean-Claude y Gaudemet, Yves (2000), Droit Administratif (16 ed.). Paris:, L.G.D.J.

- Marinoni, Luiz, Pérez, Álvaro y NúÑez, Raúl (2010), Fundamentos del proceso civil. Hacia una teoría de la adjudicación. Santiago de Chile: Abeledo Perrot-LegalPublishing. 
- Marshall, Pablo (2010), "El efecto horizontal de los derechos y la competencia del juez para aplicar la Constitución", Estudios Constitucionales 8/1, pp. 43-78.

- Martínez, José Ignacio (2005), "Recurso de inaplicabilidad, Tribunal Constitucional y juez ordinario en la reforma constitucional", en Nogueira, Humberto (coord.), La Constitución reformada de 2005. Santiago de Chile: Librotecnia, pp. 457-472.

- Montt, Ambrosio (1895), Dictamenes del Fiscal de la Corte Suprema de Justicia de Chile Ambrosio Montt. Santiago de Chile: Imprenta Nacional.

- Mortati, Constantino (1991), Istituzioni di Diritto pubblico (10 a ed., a cura di F. Modugno, A. Baldasarre y C. Mezzanotte). Padova: Cedam.

- Muguerza, Javier (1994), "El Tribunal de la conciencia y la conciencia del tribunal (una reflexión ético-jurídica sobre la ley y la conciencia”, Doxa 15/16, pp. 535-559.

- Nieto, Alejandro (1983), "Peculiaridades jurídicas de la norma constitucional”, Revista de Administración Pública 100-102, pp. 371415.

- Nino, Carlos Santiago (1995), Introducción al análisis del Derecho. Buenos Aires: Astrea.

- Nogueira, Humberto (2008), Derechos fundamentales y garantías constitucionales. Santiago de Chile: Librotecnia.

- NúŃEz, Manuel (2008), "El control de la igualdad en la aplicación de la ley como factor de expansión del control concreto de constitucionalidad de las leyes", en Fermandois, A. (ed.), Sentencias destacadas 2007. Una mirada desde la perspectiva de las politicas públicas. Santiago de Chile: Ed. Libertad y Desarrollo, pp. 123-161.

- Núñez, Manuel (2012), "Los efectos de las sentencias en el proceso de inaplicabilidad en Chile: examen a un quinquenio de la reforma constitucional", Estudios Constitucionales 12/1, pp. 15-64

- Pagotto, Cesare (2008), La disaplicazione della legge. Milano: Giuffrè.

- Pedreira, Félix (2007), Problemas fundamentales del delito de prevaricación judicial. Doctrina y jurisprudencia. Madrid: Ed. Ramón Areces.

- Pfeffer, Emilio (2011), "La inaplicabilidad, ¿un seudoamparo de derechos fundamentales?", en Asociación Chilena de Derecho Constitucional, Estudios sobre justicia constitucional. Libro homenaje a la Profesora Luz Bulnes Aldunate. Santiago de Chile: Edit. Jurídica de Chile, pp. 203-224.

- Pica, Rodrigo (2009), "El carácter concreto del control de inaplicabilidad por inconstitucionalidad en el Derecho chileno", 
Revista de Derecho de la Universidad Católica del Norte 16/2, pp. 101136.

- Piedrabuena, Guillermo (2008), Ley 20.253. Agenda corta antidelincuencia. Santiago de Chile: Pontificia Universidad CatólicaLegis.

- Ríos, Lautaro (2002), "El control difuso de la constitucionalidad de la ley en la República de Chile", Gaceta Jurídica 264, pp. 20-43 (también publicado en Ius et Praxis 8/1, pp. 389-418).

- Ríos, Lautaro (2005), Las dos caras de Jano y otros ensayos. Valparaíso: Edeval.

- Rodríguez, Luis y Ossandón, María (2008), Delitos contra la función pública (2a ed.). Santiago de Chile: Ed. Jurídica de Chile.

- Roldán, Alcibíades (1913), Elementos de derecho constitucional de Chile. Santiago de Chile: Imprenta Litografía.

- Romero, Alejandro (2005), "El recurso de casación en el fondo como medio para denunciar la infracción a la Constitución", Revista Chilena de Derecho 32/3, pp. 495-500.

- Ruiz Tagle, Pablo (1998-1999), "Control constitucional concentrado y difuso: El uso de una dicotomía ruinosa”, Revista de Derecho público 61, pp. 81-95.

- Saenger, Fernando y Bruna, Guillermo (2006), Inaplicabilidad por inconstitucionalidad. Jurisprudencia 1980-2005. Santiago de Chile: Ed. Jurídica de Chile.

- Schmitt, Carl (1998), La defensa de la Constitución (trad. M. Sánchez). Madrid: Tecnos.

- Silva, Luis Alejandro (2007), "Insuficiencia del principio de supremacía constitucional en el control de constitucionalidad de los actos administrativos", Estudios Constitucionales 5/1, pp. 283-304.

- Silva, Luis Alejandro (2009), El control de constitucionalidad de los actos administrativos legales. Santiago de Chile: LegalPublishing.

- Silva, Luis Alejandro (2012), “¿Es el Tribunal Constitucional el supremo intérprete de la Constitución?”, Revista de Derecho de la Pontificia Universidad Católica de Valparaiso XXXVIII, pp. 573-616.

- Sorrentino, Federico (1996), Profili constituzionali dell'integrazione comunitaria. Torino: Giappichelli.

- Soto Kloss, Eduardo (1996), Derecho administrativo. Bases fundamentales. El principio de juridicidad. Santiago de Chile: Ed. Jurídica de Chile.

- SuÁrez S.J., Francisco (1967), Tratado de las leyes y de Dios legislador [1612], vol. IV (trad. José Eguillor). Madrid: Instituto de Estudios Políticos. 
- Van Weezel, Alex (2001), “¿Es inconstitucional el artículo 450, inciso primero del Código Penal?”, Revista Chilena de Derecho 28/1, pp. 206-211.

- Verdugo, Sergio (2010): "Inaplicabilidad y vicios de forma. ¿Un problema resuelto?, Revista de Derecho (Universidad Austral, Valdivia) XXIIII/2, pp. 83-112.

- Viala, Alexandre (1999), Les réserves d'interprétation dans la jurisprudence du Conseil constitutionnel. Paris: LGDJ.

- Viala, Alexandre (2001), “De la dualité du 'sein' et du 'sollen' pour mieux comprenderé l'autorité de la chose intérpretée”, Revue du Droit Public 117/3, pp. 777-810

- Zagrebelsky, Gustavo (1990), Diritto costituzionale. Il sistema delle fonti del diritto. Torino: UTET.

- Zagrebelsky, Gustavo (2008), La legge e la sua giustizia. Bologna: Il Mulino.

- Zúñiga, Francisco (2005), "Control de constitucionalidad y casación”, Estudios Constitucionales 3/2, pp-15-27

- ZúNiga, Francisco (2006), Control de constitucionalidad y sentencia, en Cuadernos del Tribunal Constitucional 34.

- Zúñiga, Francisco (2010a), Acciones de inaplicabilidad e inconstitucionalidad. Doctrina y jurisprudencia del Tribunal Constitucional sobre temas procesales. Santiago de Chile: AbeledoPerrot-LegalPublishing.

- ZúŃIgA, Francisco (2010b), "La relación Tribunal ConstitucionalTribunales del fondo y los efectos de la sentencia de inaplicabilidad acerca de los presupuestos de la acción", en Nogueira, Humberto (Coord.), Temas de Derecho Procesal Constitucional. Reflexiones juridicas sobre competencias del Tribunal Constitucional y la nueva LOC del Tribunal Constitucional. Santiago de Chile: Librotecnia, pp. 263-353. 